\title{
Instrumentation for Remote Monitoring and Control of Liquid-Fed Ceramic Melters
}

\author{
J. H. Westsik, Jr. \\ B. M. Wise \\ G. E. Spanner \\ S. M. Barnes
}

December 1985

Prepared for the U.S. Department of Energy under Contract DE-AC06-76RLO 1830

Pacific Northwest Laboratory Operated for the U.S. Department of Energy by Battelle Memorial Institute 


\title{
DISCLAIMER
}

This report was prepared as an account of work sponsored by an agency of the United States Government. Neither the United States Government nor any agency thereof, nor any of their employees, makes any warranty, express or implied, or assumes any legal liability or responsibility for the accuracy, completeness, or usefulness of any information, apparatus, product, or process disclosed, or represents that its use would not infringe privately owned rights. Reference herein to any specific commercial product, process, or service by trade name, trademark, manufacturer, or otherwise, does not necessarily constitute or imply its endorsement, recommendation, or favoring by the United States Government or any agency thereof. The views and opinions of authors expressed herein do not necessarily state or reflect those of the United States Government or any agency thereof.

\author{
PACIFIC NORTHWEST LABORATORY \\ operated by \\ BATTELLE \\ for the \\ UNITED STATES DEPARTMENT OF ENERGY \\ under Contract DE-AC06-76RLO 1830
}

\begin{tabular}{|c|c|}
\hline \multirow{2}{*}{\multicolumn{2}{|c|}{ Printed in the United States of America }} \\
\hline \multirow{2}{*}{\multicolumn{2}{|c|}{$\begin{array}{l}\text { Available from } \\
\text { National Technical Information Service }\end{array}$}} \\
\hline & \\
\hline \multirow{2}{*}{\multicolumn{2}{|c|}{5285 Port Royal Road }} \\
\hline & \\
\hline \multicolumn{2}{|c|}{ Springfield, Virginia 22161} \\
\hline \multicolumn{2}{|c|}{ NTIS Price Codes } \\
\hline & \\
\hline \multicolumn{2}{|c|}{ Printed Copy } \\
\hline & Price \\
\hline Pages & Codes \\
\hline $001-025$ & $\mathrm{~A} 02$ \\
\hline $026-050$ & $\mathrm{~A} 03$ \\
\hline $051-075$ & A04 \\
\hline $076-100$ & A05 \\
\hline $101-125$ & $A 06$ \\
\hline $126-150$ & $\mathrm{~A} 07$ \\
\hline $151-175$ & $\mathrm{~A} 0 \mathrm{~B}$ \\
\hline $176-200$ & A09 \\
\hline $201-225$ & A010 \\
\hline $226-250$ & A011 \\
\hline $251-275$ & A012 \\
\hline $276-300$ & $\mathrm{~A} 013$ \\
\hline
\end{tabular}


INSTRUMENTATION FOR REMOTE MONITORING AND CONTROL OF LIQUID-FED CERAMIC MELTERS

\author{
J. H. Westsik, Jr. \\ B. M. Wise \\ G. E. Spanner \\ S. M. Barnes
}

December 1985

Prepared for

the U.S. Department of Energy

under Contract DE-AC06-76RLO 1830

\footnotetext{
Pacific Northwest Laboratory
} Richland, Washington 99352 
New and existing instrumentation for the monitoring and control of the liquid-fed ceramic melter (LFCM) process have been tested and evaluated. The use of thermocouples for the monitoring of the glass melting process to assure a quality product and to monitor the condition of the melter equipment is well developed. Additional information about the operation of the melter including foaming, feeding, and cold cap coverage can be obtained from the temperature data. A melter viewing system consisting of an infrared camera and associated electronics has been demonstrated to provide clear pictures of the melter interior and cold cap surface during melter operation. The pneumatic level detection system functions well for measuring glass specific gravity and glass level in the melter. Further testing is needed to assess its capabilities for indicating overfeeding, bridging of the cold cap, and foaming. Acoustic monitoring was examined for detection of foaming and overfeeding, and time domain reflectometry was considered for detection of glass level, foaming, and salt formation. 


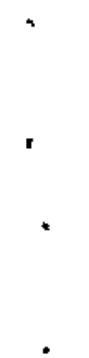

$+$ $+$ 


\section{CONTENTS}

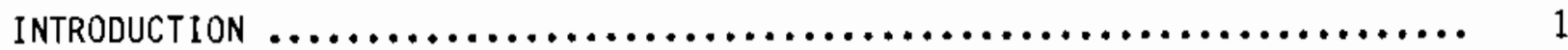

DESCRIPTION OF MELTER SYSTEM $\ldots \ldots \ldots \ldots \ldots \ldots \ldots \ldots \ldots \ldots \ldots \ldots \ldots \ldots \ldots \ldots \ldots \ldots \ldots \ldots \ldots \ldots$

THERMOCOUPLES AND THERMOWELLS $\ldots \ldots \ldots \ldots \ldots \ldots \ldots \ldots \ldots \ldots \ldots \ldots \ldots \ldots \ldots \ldots$

EQUIPMENT DESCRIPTION $\ldots \ldots \ldots \ldots \ldots \ldots \ldots \ldots \ldots \ldots \ldots \ldots \ldots \ldots \ldots \ldots \ldots \ldots \ldots \ldots \ldots \ldots \ldots$

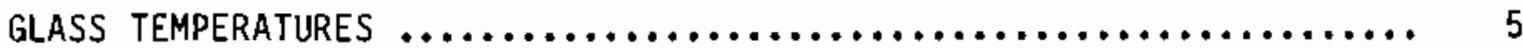

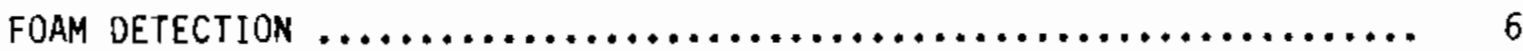

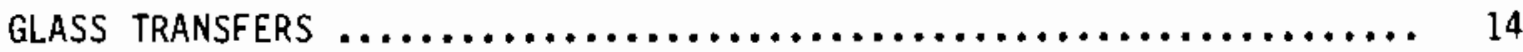

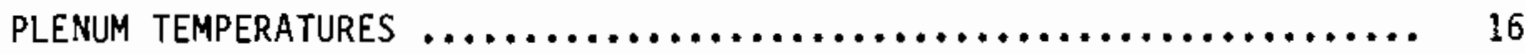

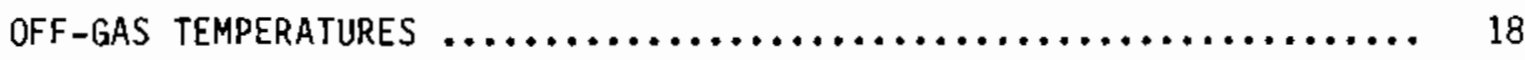

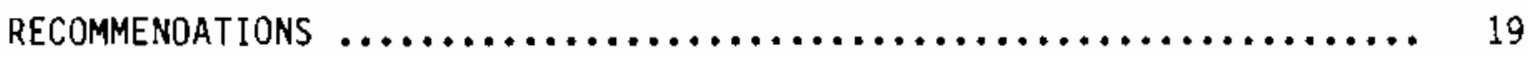

PNEUMATIC LEVEL OETECTION SYSTEM $\ldots \ldots \ldots \ldots \ldots \ldots \ldots \ldots \ldots \ldots \ldots \ldots \ldots \ldots \ldots$

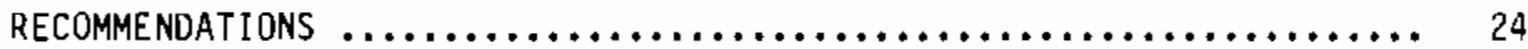

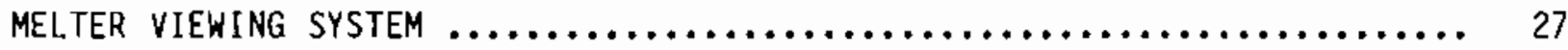

EQUIPMENT OESCRIPTION $\ldots \ldots \ldots \ldots \ldots \ldots \ldots \ldots \ldots \ldots \ldots \ldots \ldots \ldots \ldots \ldots \ldots \ldots \ldots \ldots \ldots \ldots$

INITIAL PERFORMANCE CHARACTERIZATION $\ldots \ldots \ldots \ldots \ldots \ldots \ldots \ldots \ldots \ldots \ldots \ldots$

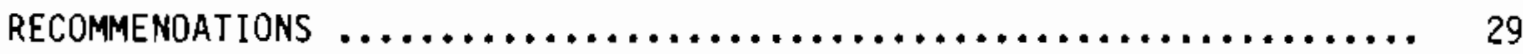

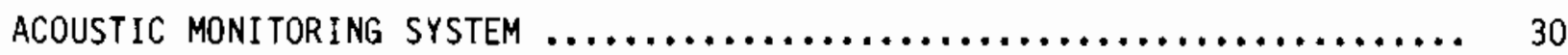

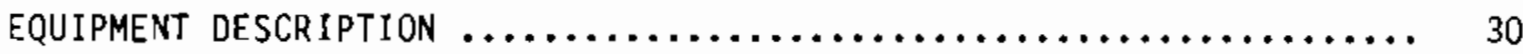

INITIAL PERFORMANCE CHARACTERIZATION $\ldots \ldots \ldots \ldots \ldots \ldots \ldots \ldots \ldots \ldots \ldots \ldots$

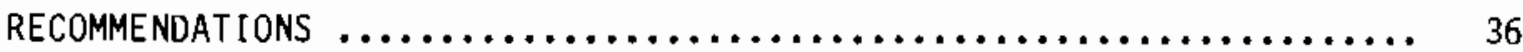

TIME-DOMAIN REFLECTOMETER LIQUID-LEVEL DETECTION SYSTEM ............ 38

EQUIPMENT AND OPERATION DESCRIPTION $\ldots \ldots \ldots \ldots \ldots \ldots \ldots \ldots \ldots \ldots \ldots \ldots$

INITIAL PERFORMANCE CHARACTERIZATION $\ldots \ldots \ldots \ldots \ldots \ldots \ldots \ldots \ldots \ldots \ldots \ldots \ldots \ldots \ldots \ldots \ldots \ldots \ldots$

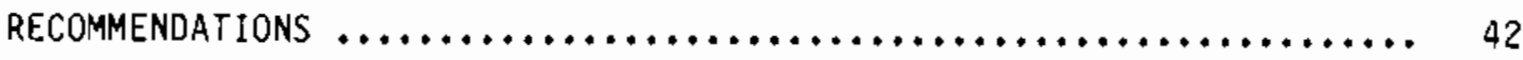




\section{FIGURES}

1 Location of Melter Instrumentation on the PSCM $\ldots \ldots \ldots \ldots \ldots \ldots \ldots, 4$

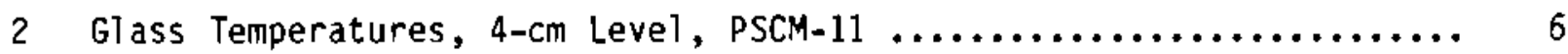

3 Glass Temperatures, 8 -cm Leve1, PSCM-11 $\ldots \ldots \ldots \ldots \ldots \ldots \ldots \ldots, 7$

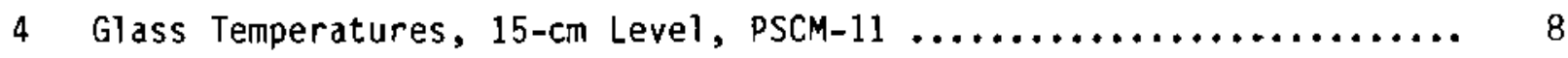

5 Glass Temperatures, $23-\mathrm{cm}$ Level, PSCM-11 .................... 9

6 Glass Temperatures, $30-\mathrm{cm}$ Level, PSCM-11 $\ldots \ldots \ldots \ldots \ldots \ldots \ldots \ldots . . . . . .10$

7 Glass Temperatures, $38-\mathrm{Cm}$ Leve1, PSCM-11 .................. 11

8 Glass Temperatures, $46-\mathrm{cm}$ Level, PSCM-11 $\ldots \ldots \ldots \ldots \ldots \ldots \ldots \ldots, 12$

9 Vertical Temperature Profiles in PSCM Glass Melter $\ldots \ldots \ldots \ldots \ldots \ldots . . . .13$

10 Effect of Averaging Time on RMS Temperature Fluctuation at

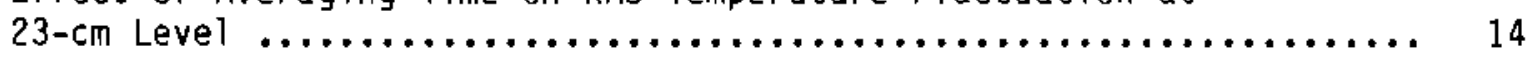

11 Root-Mean-Square of Temperature Fluctuations at

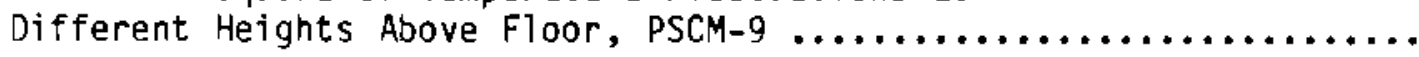

12 Root-Mean-Square of Temperature Fluctuations at

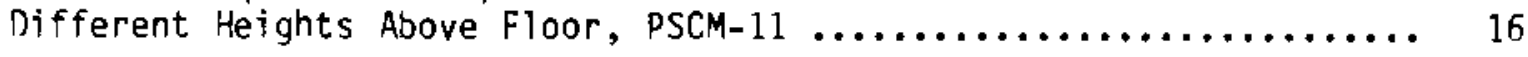

13 Multi-Point Recorder Tracing Showing Glass Temperatures During

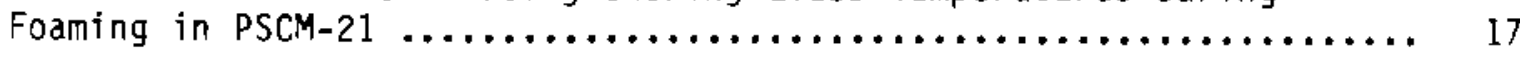

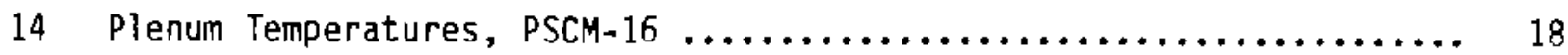

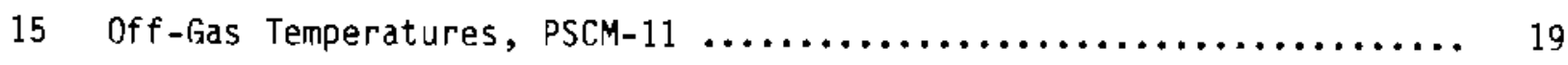

16 Glass Pneumatic Level Detection System Schematic ................ 20

17 Strip Chart Segment Showing Stability and Foam Indicator

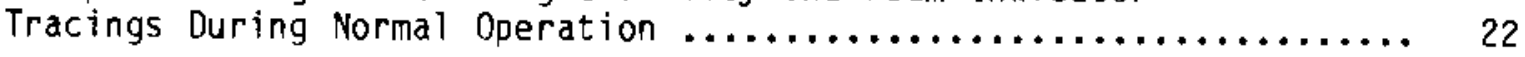

18 Stability and Foam Indicators During Foaming Incident $\ldots \ldots \ldots \ldots \ldots . .22$

19 Stability and Foam Indicators Showing Spikes Due to

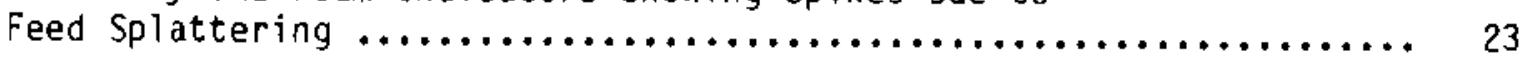

20 Strip Chart Segment Showing Stability and Foam Indicator

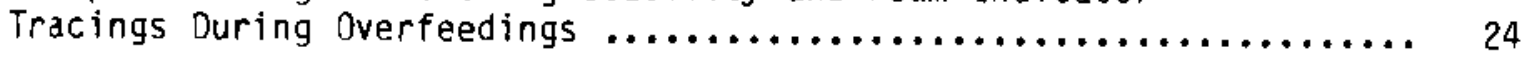

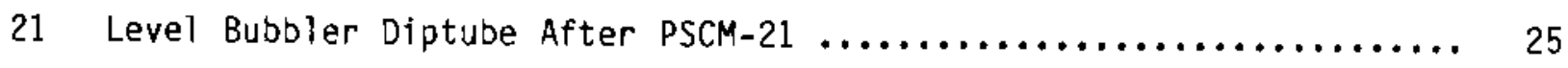


22 Level Bubbler Diptube $50-\mathrm{cm}$ Level Port After PSCM-21 ........... 25

23 Level Bubbler Diptube $20-\mathrm{cm}$ Level Port After PSCM-21 ........... 26

24 Level Bubbler Diptube $2.5-\mathrm{cm}$ Level Port After PSCM-21 .......... 26

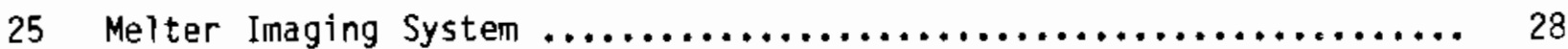

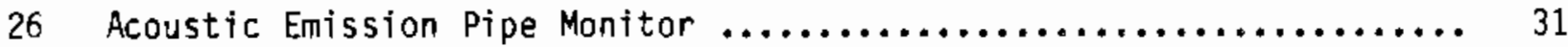

27 Functional Block Diagram of AE Pipe Monitor $\ldots \ldots \ldots \ldots \ldots \ldots \ldots \ldots \ldots$

28 Typical Graph Showing Cumulative Acoustic Events During a 105-Minute Period of PSCM-21 .......................... 35

29 Impedance Ratio Traces Showing Increasing Slurry Level .......... 39

30 Response of TDR System to Glass Foam ..................... 40

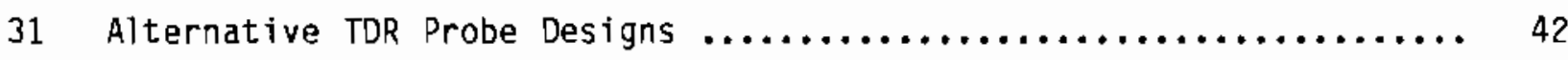


INTRODUCTION

The liquid-fed ceramic melter (LFCM) process is the reference technique being developed in the United States for the treatment of both comnercial and defense high-level radioactive wastes. In this process, the liquid wastes are mixed with glass-forming chemicals to form a slurry which is then poured directly onto the surface of molten glass. Heat from the glass dries, decomposes, and melts the slurry, adding to the glass pool. This process takes place in a crust or cold cap on the glass surface. Energy for these reactions is supplied by passing electricity directly through the molten glass and using the electrical resistance in the glass to generate the heat. Molten glass is poured in batches or continuously into steel canisters for cooling, storage, and transportation to a repository for disposal.

Development of the LFCM technology in the U.S. began at the Pacific Northwest Laboratory (PNL) in the early 1970s. The technology has been transferred to Savannah River Laboratory in South Carolina and the West Valley, New York, facility for vitrification of radioactive wastes at these sites. The technology is also being adapted for the proposed solidification facility at Hanford, Washington.

The Nuclear Waste Treatment Program at PNL has responsibility for managing civilian nuclear waste treatment activities for the U. S. Department of Energy. One objective of this program is to provide information necessary to design and operate high-level waste vitrification facilities as part of a licensed waste management system. A particular objective is to develop remote melter monitoring and control instrumentation to assure safe, efficient melter operation.

This report describes the initial development and evaluation of instrumentation packages for monitoring and control of remote melters. It is 1 imited to instrumentation for following the melting process itself, i.e., those reactions in the cold cap and molten glass. Therefore, instrumentation to monitor flow rates and compositions of the feed slurry, off gas, and glass product are not considered here.

Instruments are needed to provide indications of the melter operating status including glass level, size of cold cap, and glass temperature and to 
detect the onset of process upset conditions including excessive generation of glass foam, molten salt phase separation, and formation of a rigid cold cap over the entire glass surface (bridging). At least the detector portion of the instruments must be able to withstand the high temperatures, radiation levels, and corrosiveness of feed slurries, off gases, and glass. Because of the severe operating environment and the difficulty in repairing equipment located in a remote facility, redundant indications are required.

The instrumentation packages being developed and tested at PNL include an infrared TV camera to permit visual observation of the cold cap and melter interior, a time domain reflectometer to determine the glass level and possibly detect foaming and salt formation, a bubbler diptube to determine glass density and level and to detect foaming and bridging, an acoustic probe to detect foaming and overfeeding, and extensive use of thermocouples for numerous monitoring and control functions. 


\section{DESCRIPTION OF MELTER SYSTEM}

Most of the development and testing of the instrumentation was performed using the Pilot-Scale Ceramic Melter (PSCM) located in the Engineering Development Laboratory of the 324 Building on the Hanford Site. This melter is a Joule-heated, ceramic-lined design. It includes ancillary equipment for feeding slurry to the melter, for treatment of gaseous effluents, for collection of the glass product, and for system monitoring and control and data acquisition.

The PSCM has an exposed glass surface area of $0.73 \mathrm{~m}^{3}$ and a glass depth of approximately $42 \mathrm{~cm}$ during operation at a melter vacuum of $13-\mathrm{cm}$ water. A feed crust or cold cap up to $5-\mathrm{cm}$ thick resides on the glass surface. The melter plenum extends $110 \mathrm{~cm}$ above the glass surface.

The melter instrumentation enters the melter cavity through ports on the top of the PSCM. Figure 1 shows these ports and typical positions for the instrumentation packages. Actual locations may change depending upon the particular objectives of each melter experiment. Electrodes for passing electricity through the glass are located on the north and south walls. 


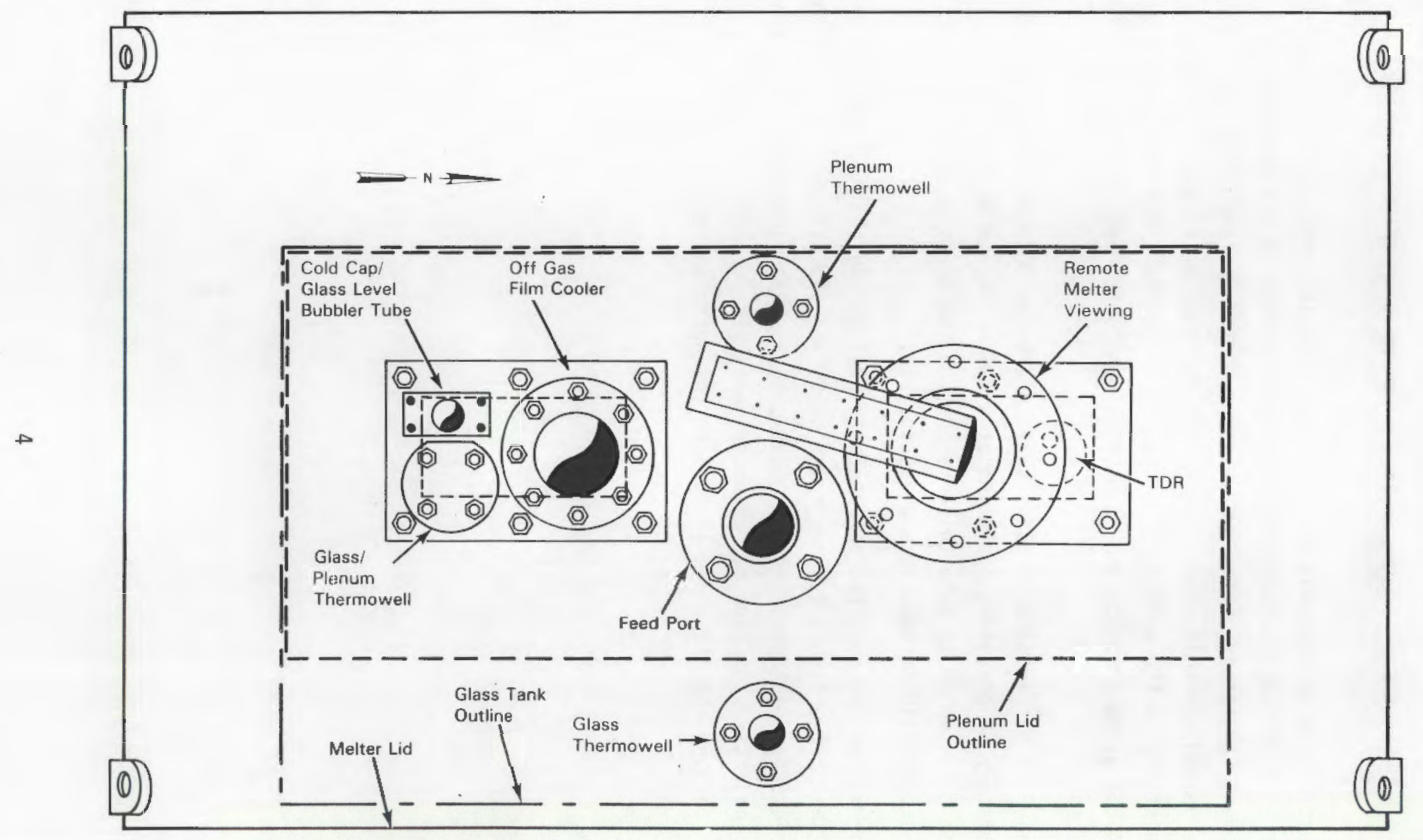

FIGURE 1. Location of Melter Instrumentation on the PSCM (Top View) 


\section{THERMOCOUPLES AND THERMOWELLS}

The thermocouple has been the primary instrument for monitoring the glass melting process. Seven thermocouples inside an Inconel pipe immersed in the glass are used to measure the glass temperatures. A second set of seven thermocouples in another Inconel pipe are located in the plenum above the glass. Thermocouples are also used to measure temperatures in the discharge area and in the off-gas treatment line. The temperatures measured at these various locations are important for the monitoring and control functions. However, additional information about the operation of the melter including foaming, feeding and cold cap coverage, and glass transfers can be inferred from these temperatures.

\section{EQUIPMENT DESCRIPTION}

Type K, ungrounded, sheathed thermocouples are used at PNL for measuring glass, plenum, and equipment temperatures in the PSCM. These Chromel/Alumel thermocouples have a maximum useful temperature range of -200 to $1250^{\circ} \mathrm{C}$. Savannah River Laboratory is using Type B thermocouples because of considerations of long-term drift and longevity (Heckendorn 1983). Because of frequent replacement requirements (4-6 months), type $K$ is judged suitable and is more cost effective. At both labs, the thermocouples are housed in Incone 1060 thermowells to provide protection from the corrosive environments of the molten glass and the melter plenum.

Temperatures are displayed on multipoint recorders and are recorded on data acquisition systems for detailed post-run analysis.

\section{GLASS TEMPERATURES}

Glass temperatures in the PSCM are usually measured with seven thermocouples located $4,8,15,23,30,38$, and $46 \mathrm{~cm}$ above the melter floor inside a 2.5-cm 0.D., 0.6-cm thick, sealed Inconel 690 pipe suspended from a flange on top of the melter. This thermowell is normally equidistance from the two

\footnotetext{
-Huntington Alloys Corp., Huntington, West Virginia.
} 
electrodes directly in front of the discharge port and $8 \mathrm{~cm}$ from the wall separating the melter tank and the glass discharge area. During melter operation, glass temperatures are monitored to assure that they are within the range necessary to produce a quality product and to assure stable melter operation. The temperatures are displayed as a function of time on a multipoint recorder so that the operators can observe the trends. From a temperature/time display such as this, incidents of foaming and glass transfers are detectable.

\section{FOAM DETECTION}

Figures 2 to 8 show the glass temperatures measured at the different levels in the melter during a 24-hour period of a melter run designated PSCM-11. Foaming and glass transfers can be identified as broad and sharp peaks in the temperature curves. Foaming is characterized by an increase in the glass

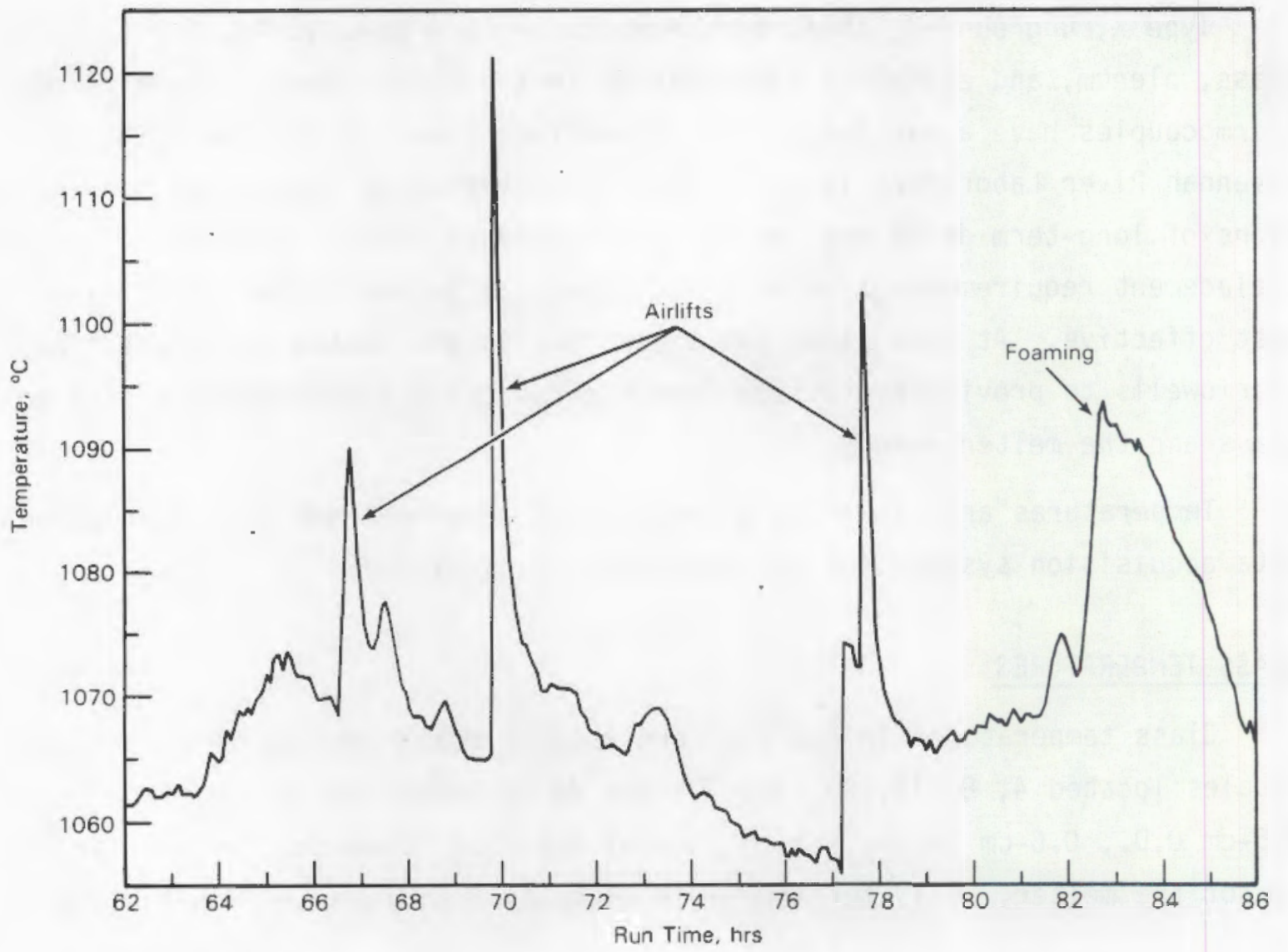

FIGURE 2. Glass Temperatures, 4-cm Leve1, PSCM-11 


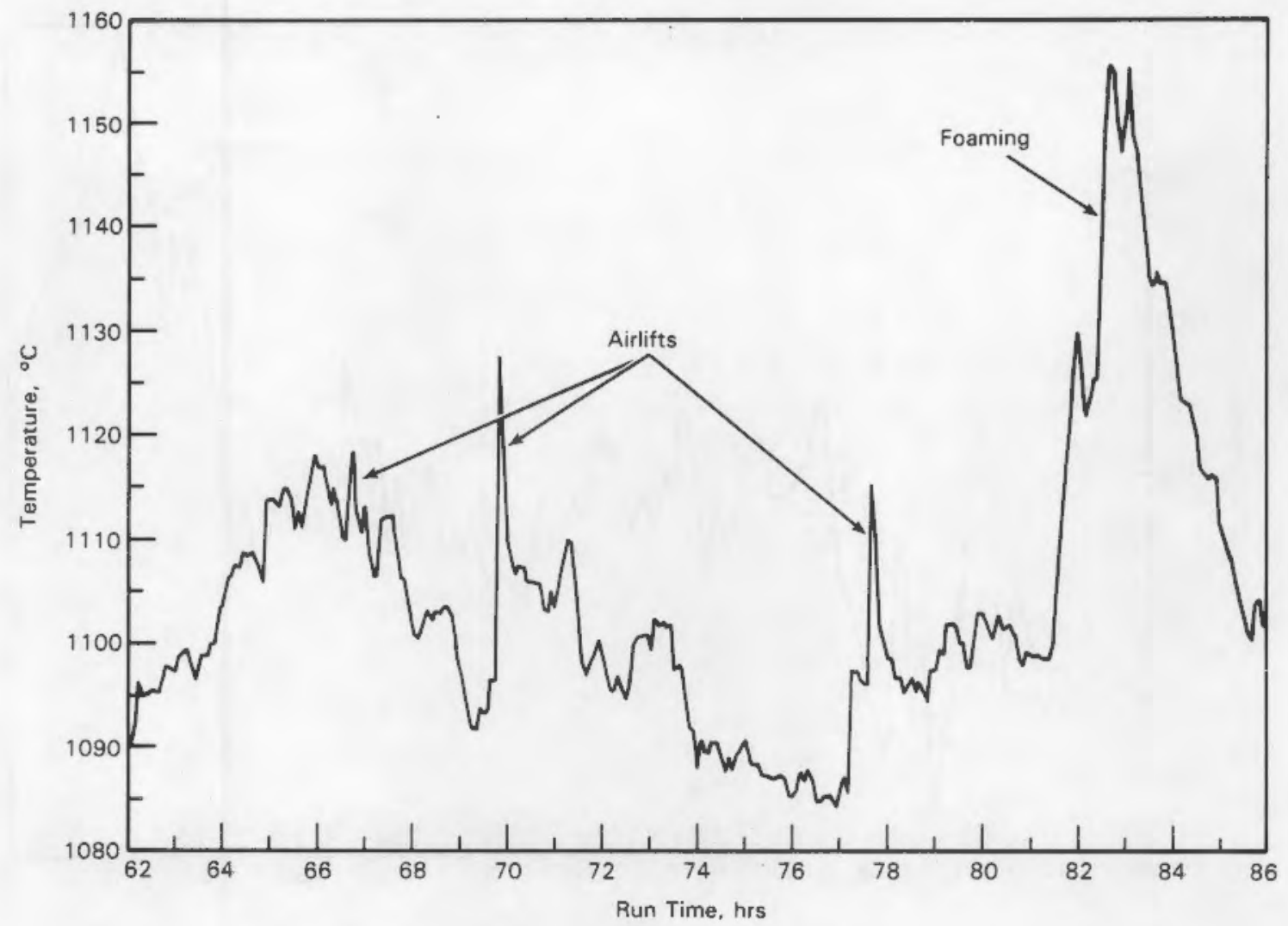

FIGURE 3. Glass Temperatures, 8-cm Level, PSCM-11

temperatures at all thermocouple levels. The increases can range from being almost imperceptible among the normal temperature fluctuations to several hundred degrees. The largest fluctuations are generally at the 38 and $46-\mathrm{cm}$ levels where the thermocouple may normally reside in the cold cap and be exposed to the higher glass temperatures as the foam rises. It is not known if corrective action by the operators prevent further temperature increases. In general, the temperature increases precede operator observations of foaming as recorded in the melter $\log$ book. The lines showing the foaming peaks in Fig. ures 2 to 8 point to the approximate time that the foaming was noted.

While the peaks associated with foaming are usually recognizable after the fact, they may not be when the temperature first begins to increase. Therefore we sought to identify some characteristics of the glass temperatures that would 


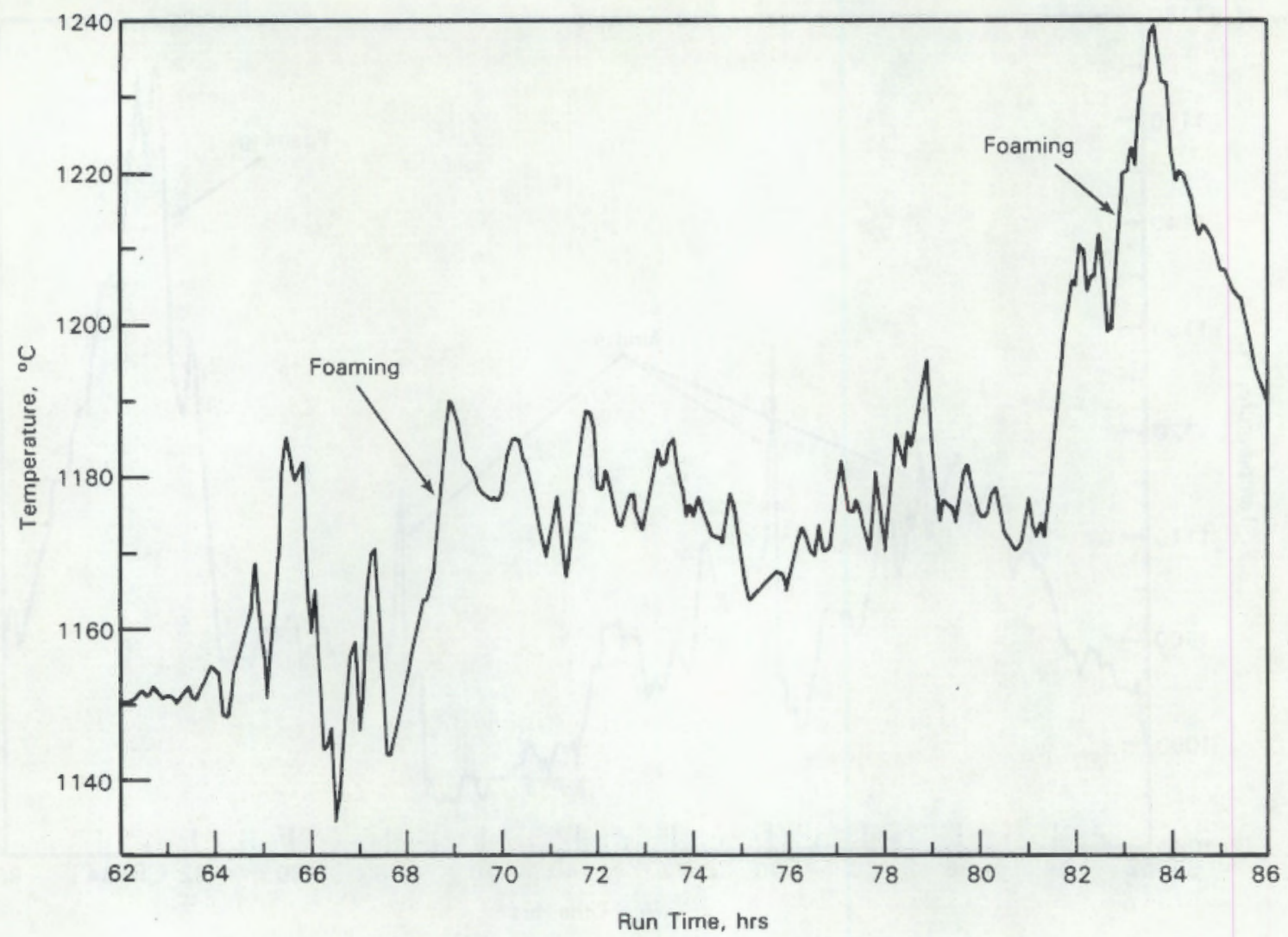

FIGURE 4. Glass Temperatures, 15-cm Level, PSCM-11

provide an earlier indication of foaming. The temperature profile in the glass, glass temperature fluctuations, and temperatures in the cold cap region were considered.

The seven thermocouples in the glass thermowell can be used to determine the temperature profile from near the melter floor to inside the cold cap above the glass. Figure 9 shows the temperature profiles before and during another two foaming incidents during PSCM-11. The profiles clearly show the large temperature increases at the 38 and $46-\mathrm{cm}$ thermocouple levels associated with the two foaming occurrences. Since the glass temperature profiles are roughly parabolic in shape, we fitted a second-order polynomial

$$
\text { Temperature }=A x^{2}+B x+C \quad(x=\text { height above melter floor })
$$




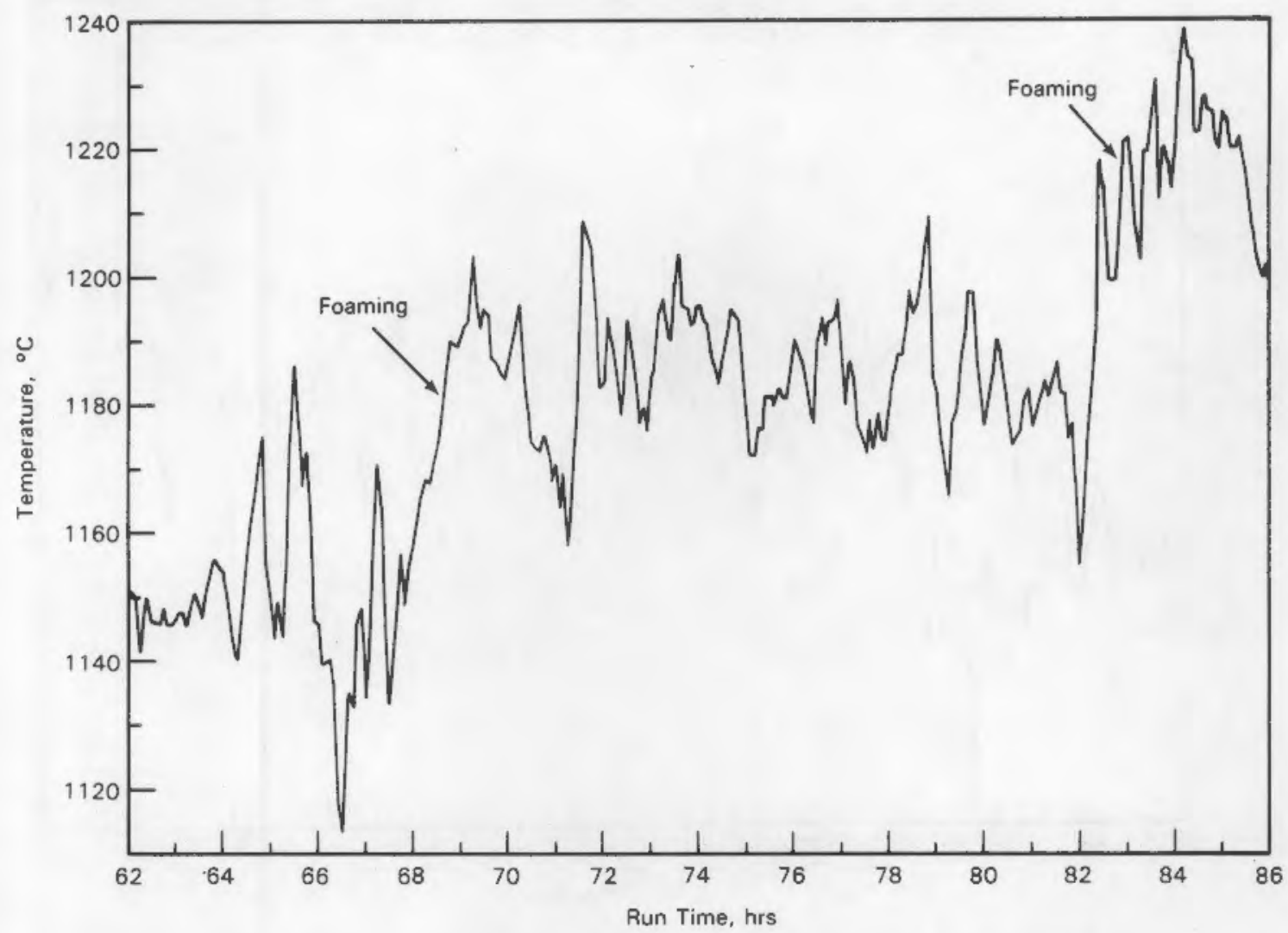

FIGURE 5. Glass Temperatures, 23-cm Level, PSCM-11

to the profiles to determine if the coefficients could be used to indicate foaming. The two foaming incidents are easily identified when the coefficients are plotted as a function of time. However, the coefficients for the secondorder polynomial appear to reflect changes at the 4 and $46-\mathrm{cm}$ thermocouples more than at the other thermocouple levels and as such are not any more valuable than observing the temperatures themselves.

As Figures 2 to 8 show, the glass temperatures fluctuate randomly, more in the middle of the melter than at the floor. The apparent rate of change of the temperatures due to the fluctuations is greater than the rate of change due to foaming except at the $4-\mathrm{cm}$ thermocouple. Therefore the rate of change in glass temperature is not itself a good indicator of foaming. Smoothing the time/ temperature curve using a half-hour time average and then examining the rate of change of the time average did not yield a good indicator either. 


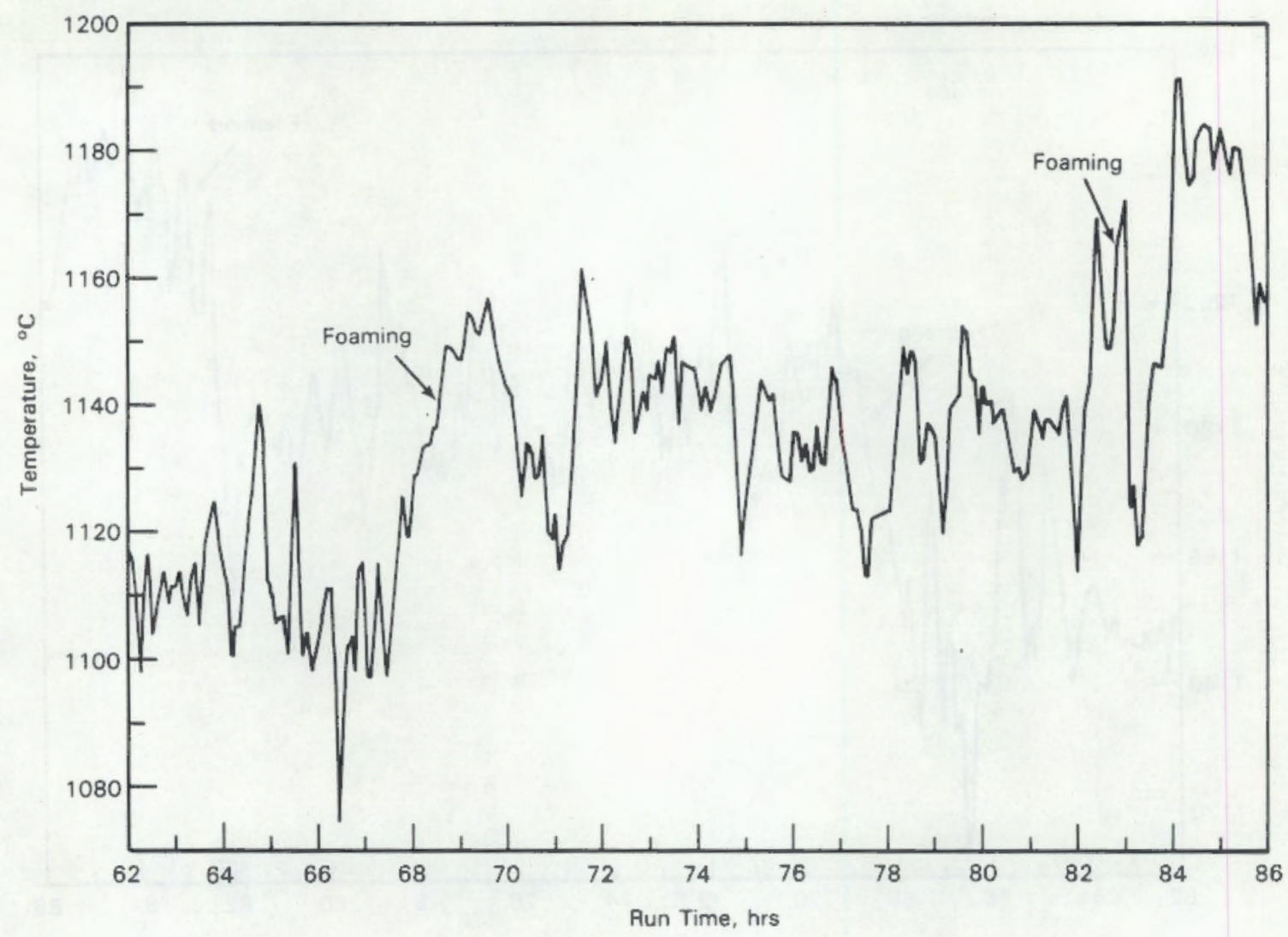

FIGURE 6. G1ass Temperatures, 30-cm Level, PSCM-11

The temperature fluctuations are a result of natural convection eddies caused by the temperature gradients in the melter. An analogy to turbulent fluid flow was used to define the magnitude of the temperature fluctuations. Intensity of turbulence is defined by the equation

$$
I=\frac{\sqrt{\overline{(u-\bar{u})^{2}}}}{\bar{v}}
$$

where $\bar{v}$ is the time-smoothed average velocity and $v$ is the instantaneous velocity (Bird, Stewart, and Lightfoot 1960). Intensity of the temperature fluctuations is determined by substituting T-instantaneous and T-average for $v$ and $\bar{v}$. The denominator should be some temperature difference characteristic of 


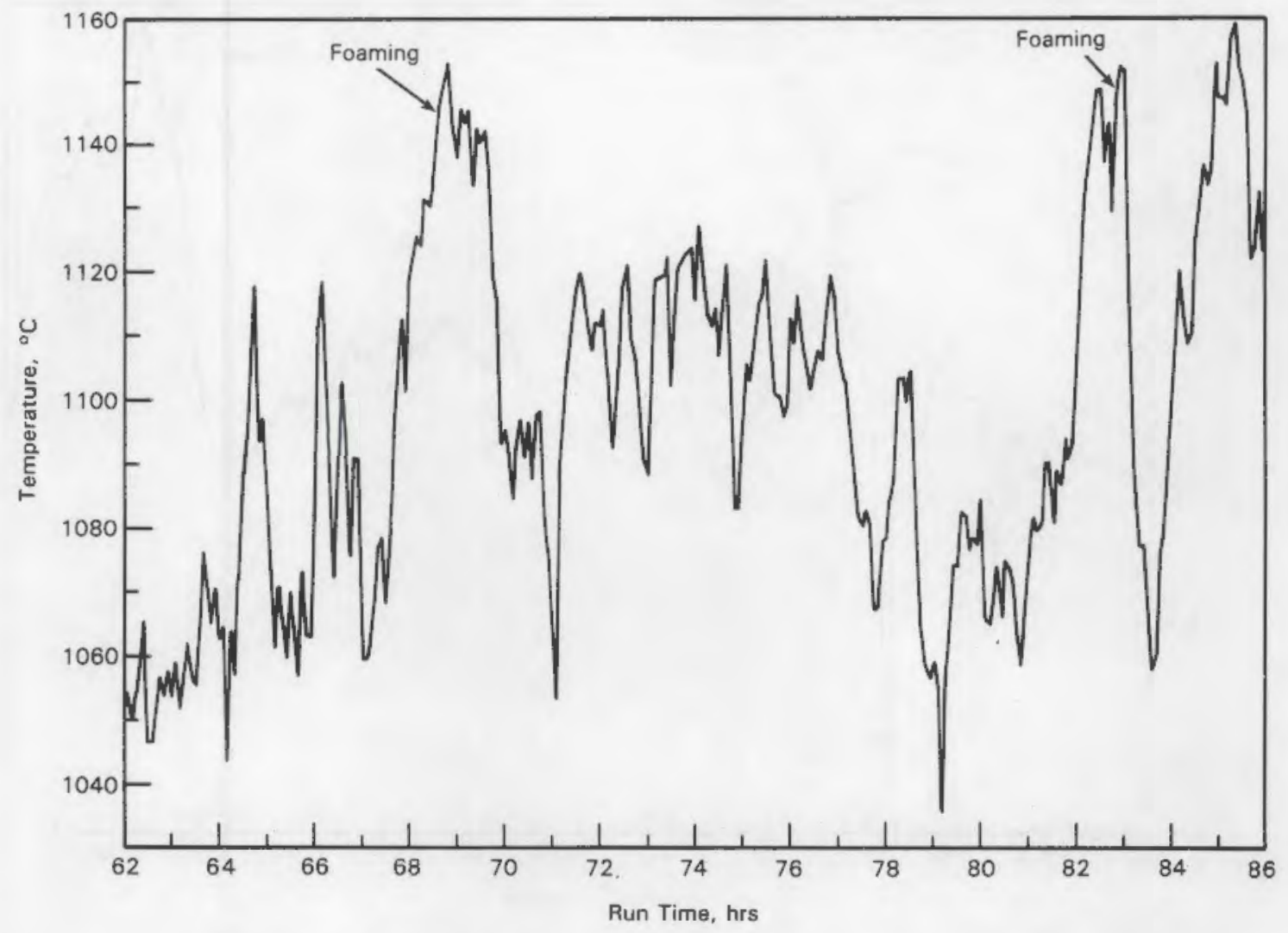

FIGURE 7. Glass Temperatures, 38-cm Level, PSCM-11

the system, but because we do not know which would be appropriate, only the numerator of the root-mean-square (RMS) of the temperature fluctuations was calculated.

Figure 10 shows how the RMS of the temperature fluctuations varied with the time period over which the temperatures were averaged. From this curve, a half hour was selected as a reasonable compromise between too short a time average and a time average so long that it would include larger temperature changes associated with foaming, etc. Figures 11 and 12 show the RMS temperature fluctuations at the different thermocouple levels for PSCM runs 9 and 11. These curves of temperature fluctuations vs position agree qualitatively with a computer code that models the convective currents in the melter. The model predicts a relatively cool, quiescent layer of glass against the melter refractories and a hotter, more turbulent region filling most of the rest of the melter. As discussed above, the 4 and $8-\mathrm{cm}$ thermocouples are located at 


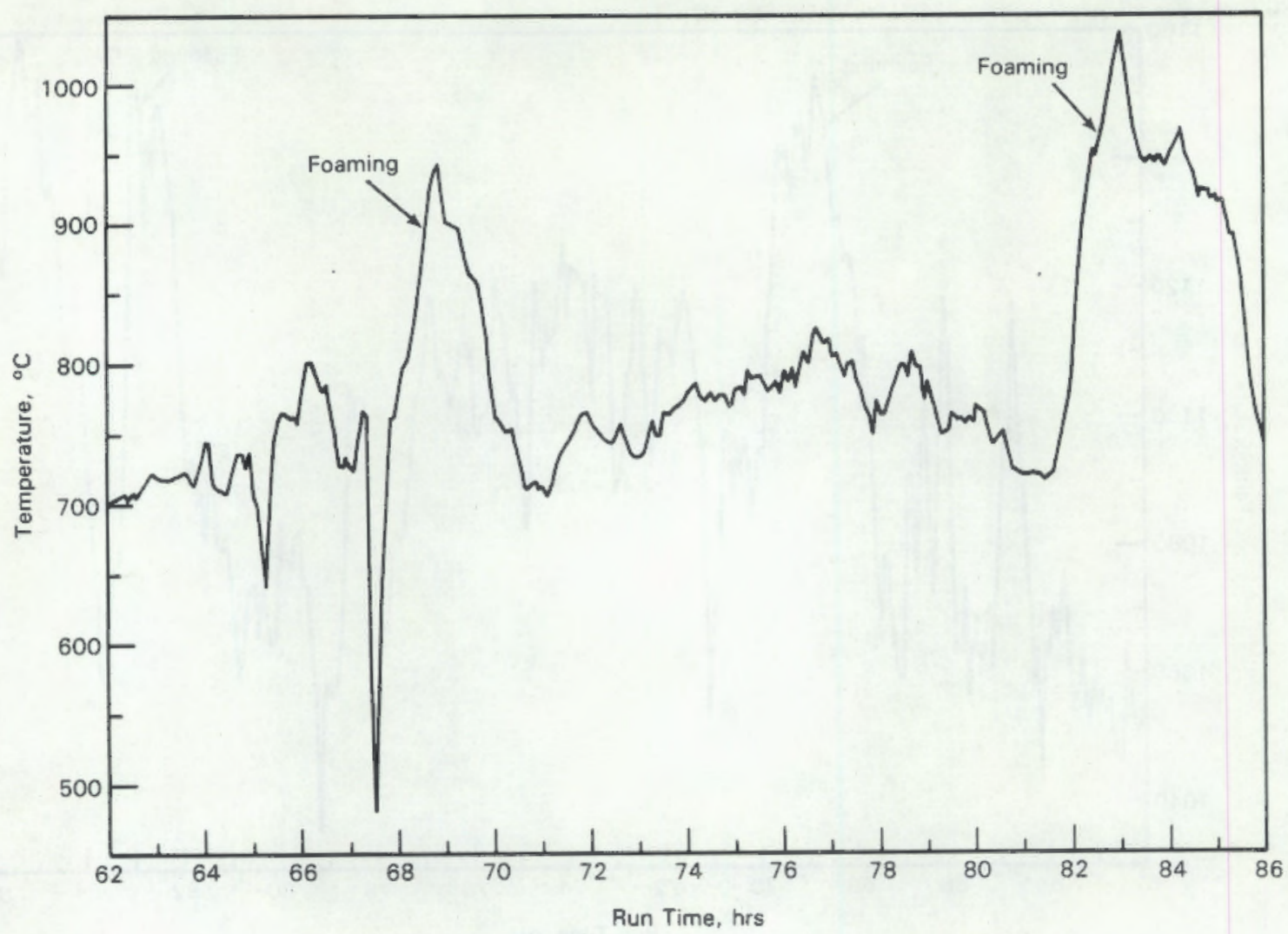

FIGURE 8. Glass Temperatures, 46-cm Level, PSCM-11

least partially within the cool boundary layer so they do not experience the larger temperature fluctuations found in the bulk of the melter. A concern remains that the entire thermowell may be in the boundary layer next to the melter tank wall.

During PSCM runs 21 and 22, the glass thermowell was located in the south rectangular port, and the thermocouples were placed at the $14,20,28,36,38$, 41 , and 43-cm levels. The four upper thermocouples were clustered in the region of the glass/cold cap interface to detect the glass level and foaming. Figure 13 shows a typical foaming incident recorded on the multipoint recorder during PSCM-21. At the height of foaming, all thermocouples were reading the same temperature, indicating that the foam level exceeded the 43-cm level. This may be the key to early detection of foaming. When the melter was idling at an average glass temperature of $1170^{\circ} \mathrm{C}$, the $43,41,38$, and $36-\mathrm{cm}$ thermocouples were reading $1040,1090,1140$, and $1170^{\circ} \mathrm{C}$, respectively. In this 


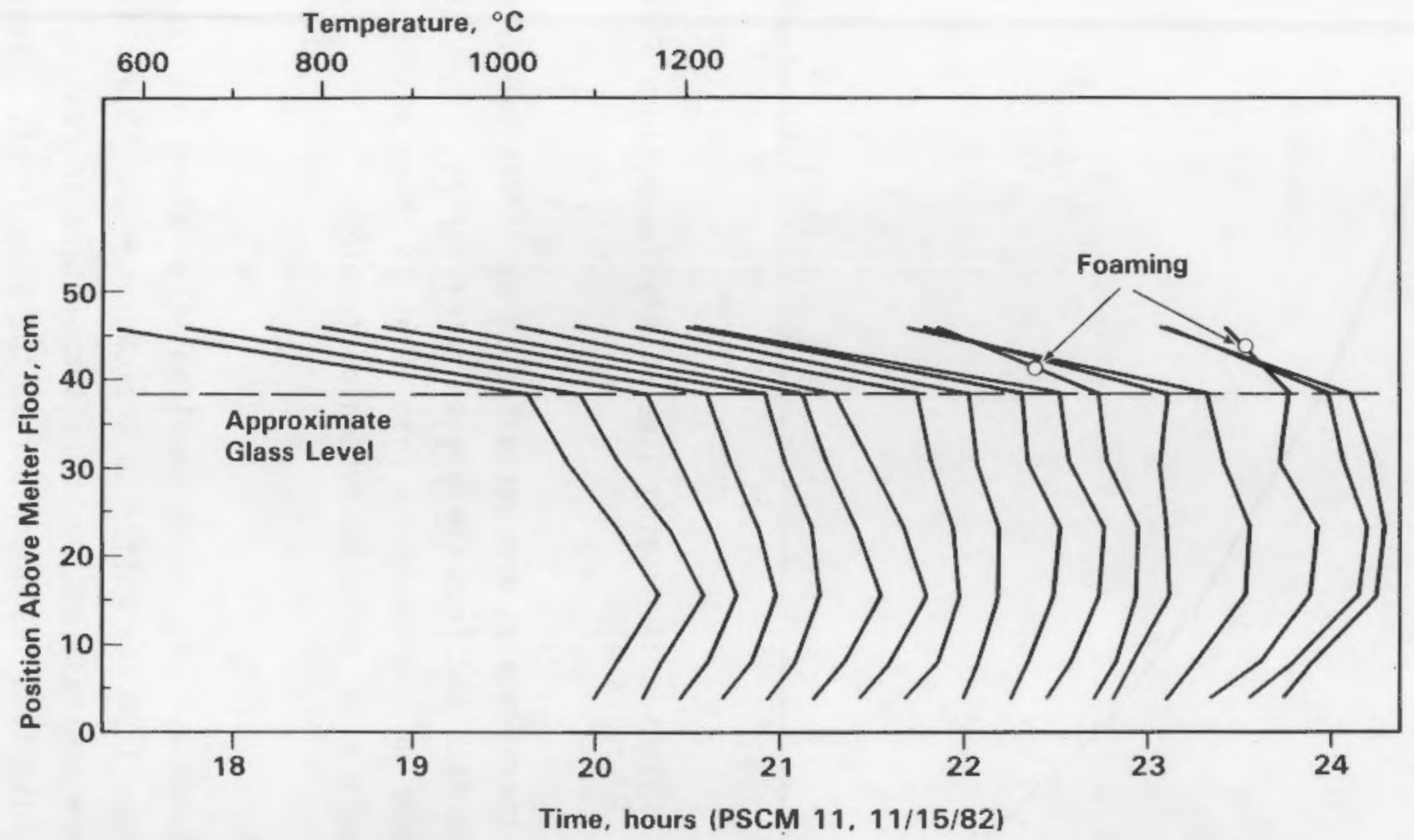

FIGURE 9. Vertical Temperature Profiles in PSCM Glass Melter. Profiles are shown at 15-minute intervals. The temperature scale shown is for the first profile. To determine the temperatures in the other profiles, off-set the temperature scale to the right for the appropriate distance for the profile of interest. For example, to determine the temperatures of the third profile, off-set the temperature scale by the length associated with 45 minutes along the time scale. 


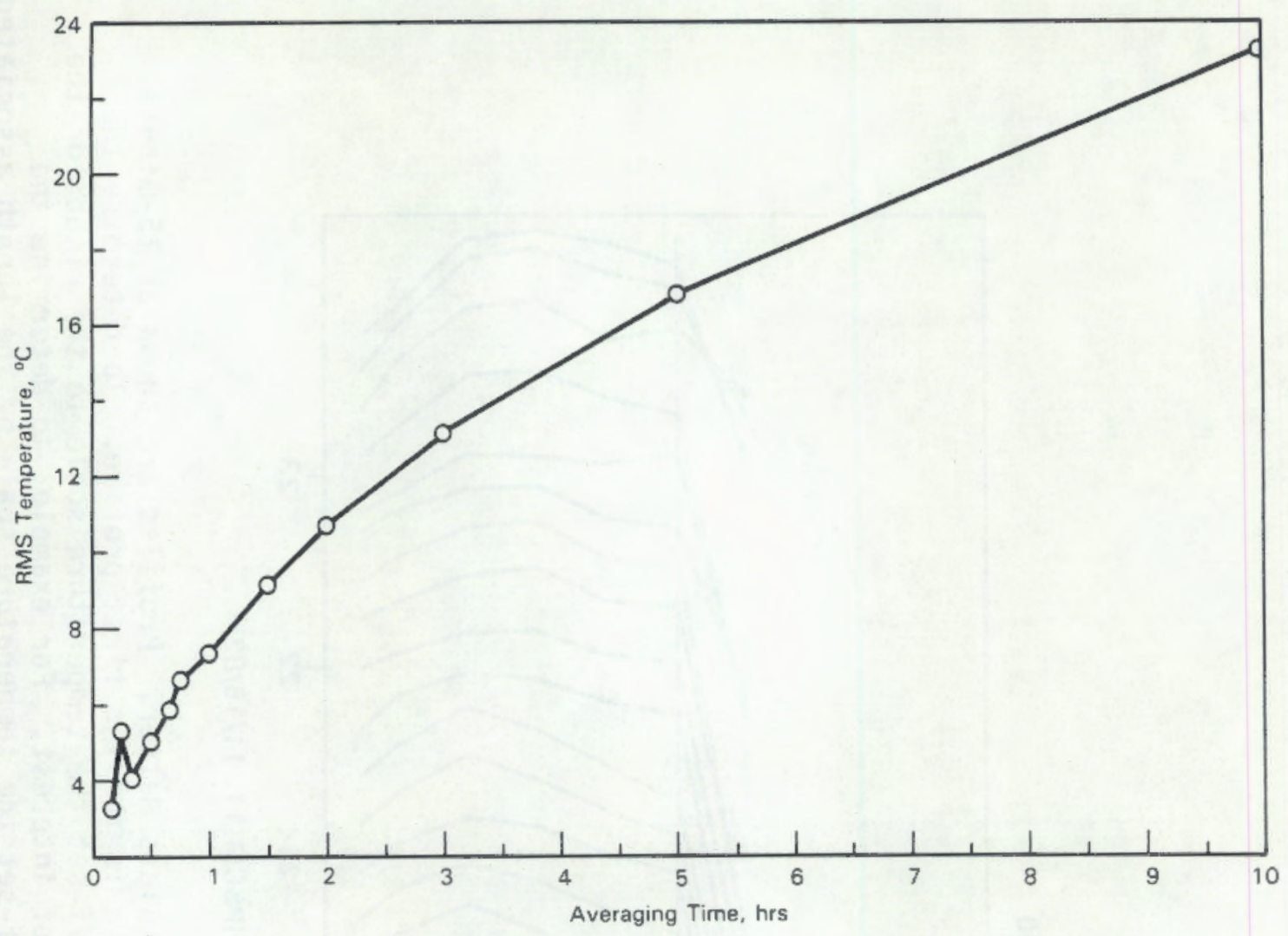

FIGURE 10. Effect of Averaging Time on RMS Temperature Fluctuation at 23-cm Level

situation, the thermocouples are being heated by direct radiation from the exposed glass surface and from the plenum refractories. These temperatures should be maximums unless the glass/foam rises to these levels and could be used as alarm points for early detection of foaming.

\section{GLASS TRANSFERS}

When the thermowell is in its usual position along the east wall, batch transfers of glass from the melter to the canister due to airlifting or a loss of off-gas vacuum are manifest by sharp temperature increases, primarily at the 4-cm level but also to a lesser extent at the $8-\mathrm{cm}$ level. These thermocouples are located just in front of the entrance to the overflow from the melter. As it exits the melter tank, relatively hot glass sweeps through a cooler, quiescent layer of glass near the floor and walls of the melter tank. Apparently, 


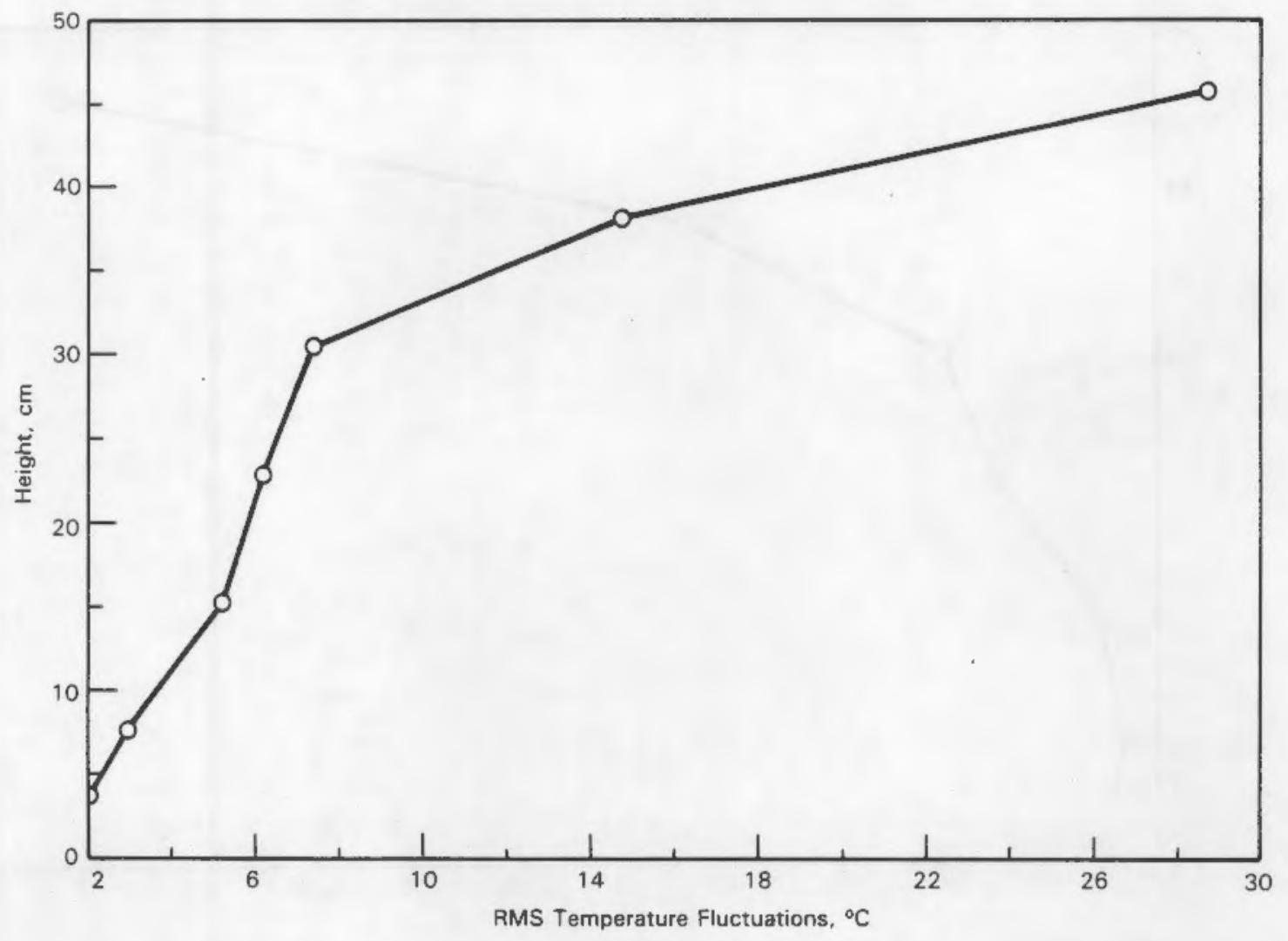

FIGURE 11. Root-Mean-Square of Temperature Fluctuations at Different Heights Above Floor, PSCM-9

the 4-cm thermocouple and, to a lesser extent, the 8-cm thermocouple lie in the cooler region such that they record the change in temperature as the glass is transferred. Theoretically, a decrease in temperature at the 38 and/or $46-\mathrm{cm}$ thermocouples would be observed as the glass level drops and these thermocouples are no longer covered by the glass. No such changes were evident in the temperature data examined for the seven equally spaced thermocouples. Temperature data collected during PSCM runs 21 and 22 with the four thermocouples clustered near the glass did show a temperature decrease with airlifts. Only the $43-\mathrm{cm}$ thermocouple measured large (greater than $300^{\circ} \mathrm{C}$ ) temperature changes and not all temperature decreases were associated with the airlifts. Glass transfers are also indicated by small temperature increases measured by thermocouples in the area of the discharge trough and discharge face. 


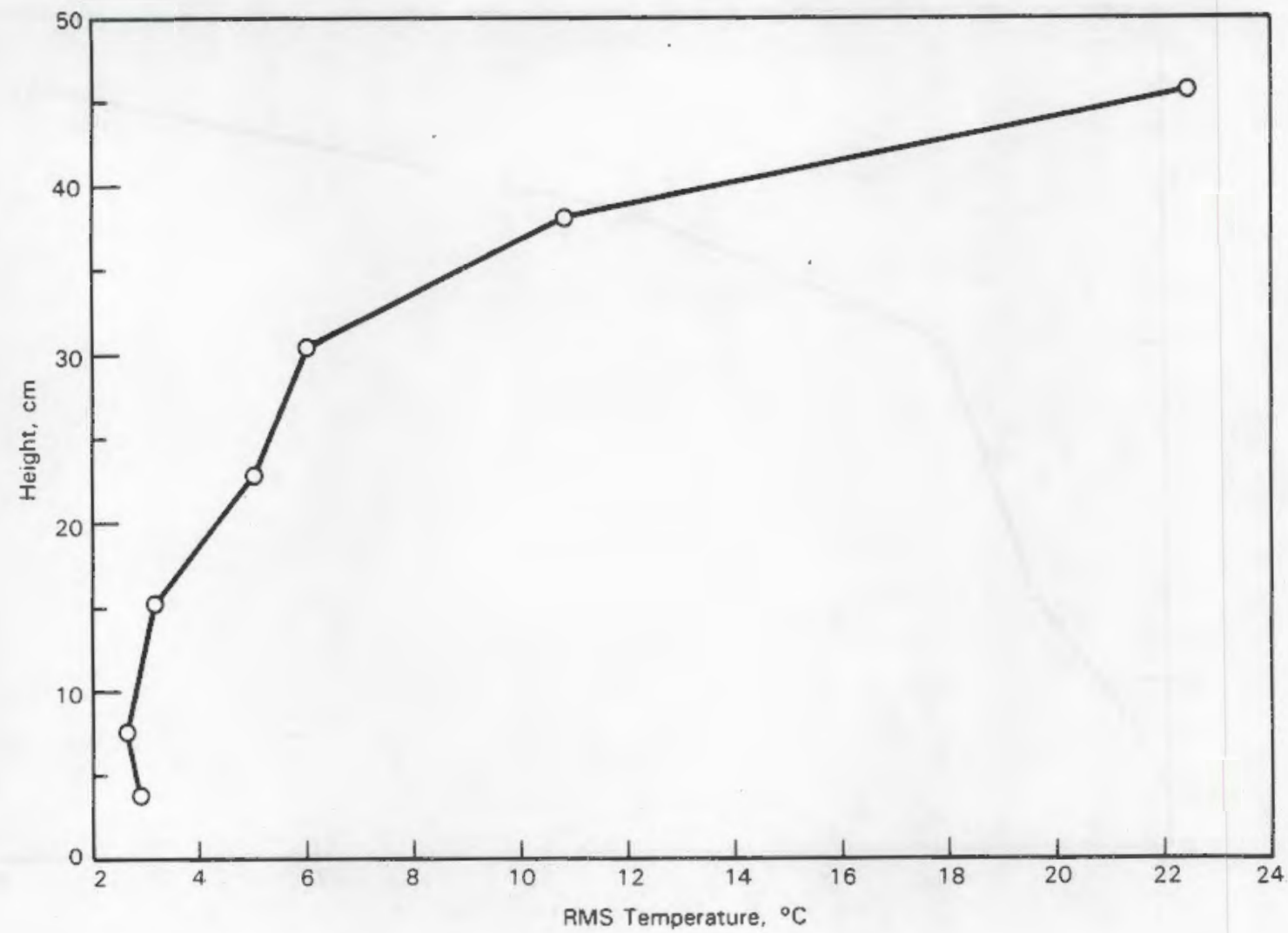

FIGURE 12. Root-Mean-Square of Temperature Fluctuations at Different Heights Above Floor, PSCM-11

\section{PLENUM TEMPERATURES}

A second thermowell, equidistance from the two electrodes and $8 \mathrm{~cm}$ from the wall opposite the glass thermowell, is used to measure temperatures in the plenum. Seven thermocouples, 69, 81, 95, 111, 121, 132, and $145 \mathrm{~cm}$ above the melter tank floor, are located inside another 2.5-cm diameter, 0.6-cm thick, sealed Inconel 690 pipe suspended from a flange on top of the melter. Additional thermocouples within the refractory also indicate trends in plenum temperatures although these temperatures do not show the fluctuations recorded by the plenum thermowell thermocouples.

Plenum temperatures appear to be affected by the condition of the cold cap. Descriptions of the cold cap in the log books are too sparse and imprecise to warrant more than a qualitative description of the response of the plenum temperatures to changes in the cold cap. Figure 14 shows plenum 


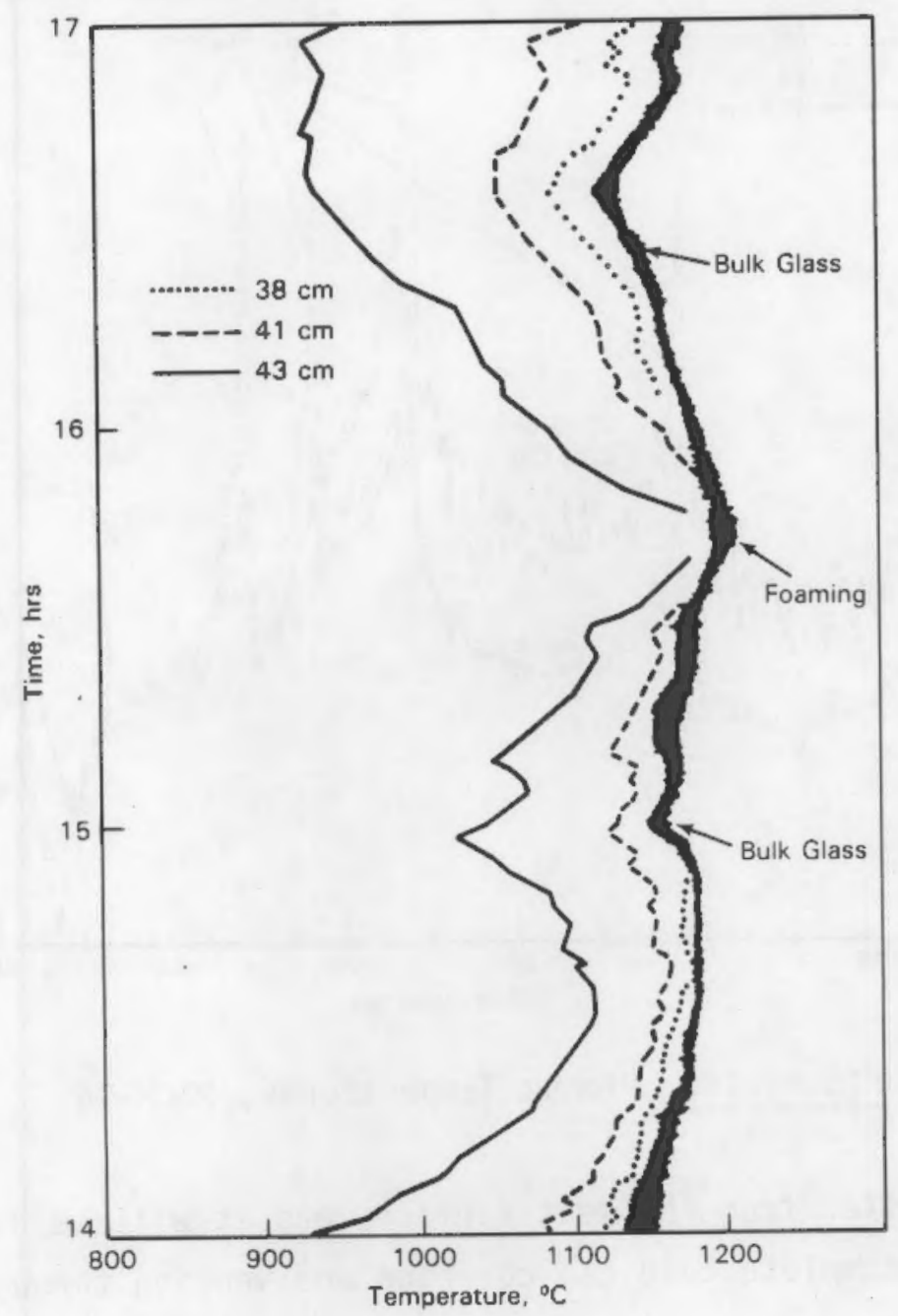

FIGURE 13. Multi-Point Recorder Tracing Showing Glass Temperatures During Foaming in PSCM-21

temperatures measured at the 69,111 , and $145-\mathrm{cm}$ levels during a 28-hour period of PSCM-16. The temperatures at the three levels tend to be farther apart the smaller the cold cap, with higher temperatures closer to the glass surface. It also appears that with complete cold cap coverage with no vents (overfeeding?) the temperature profiles in the plenum may invert with the colder temperatures measured near the cold cap surface. It may be impossible to develop a quantitative relationship between plenum temperatures and fractional cold cap coverage, particularly since the plenum temperatures are, in part, a response to 


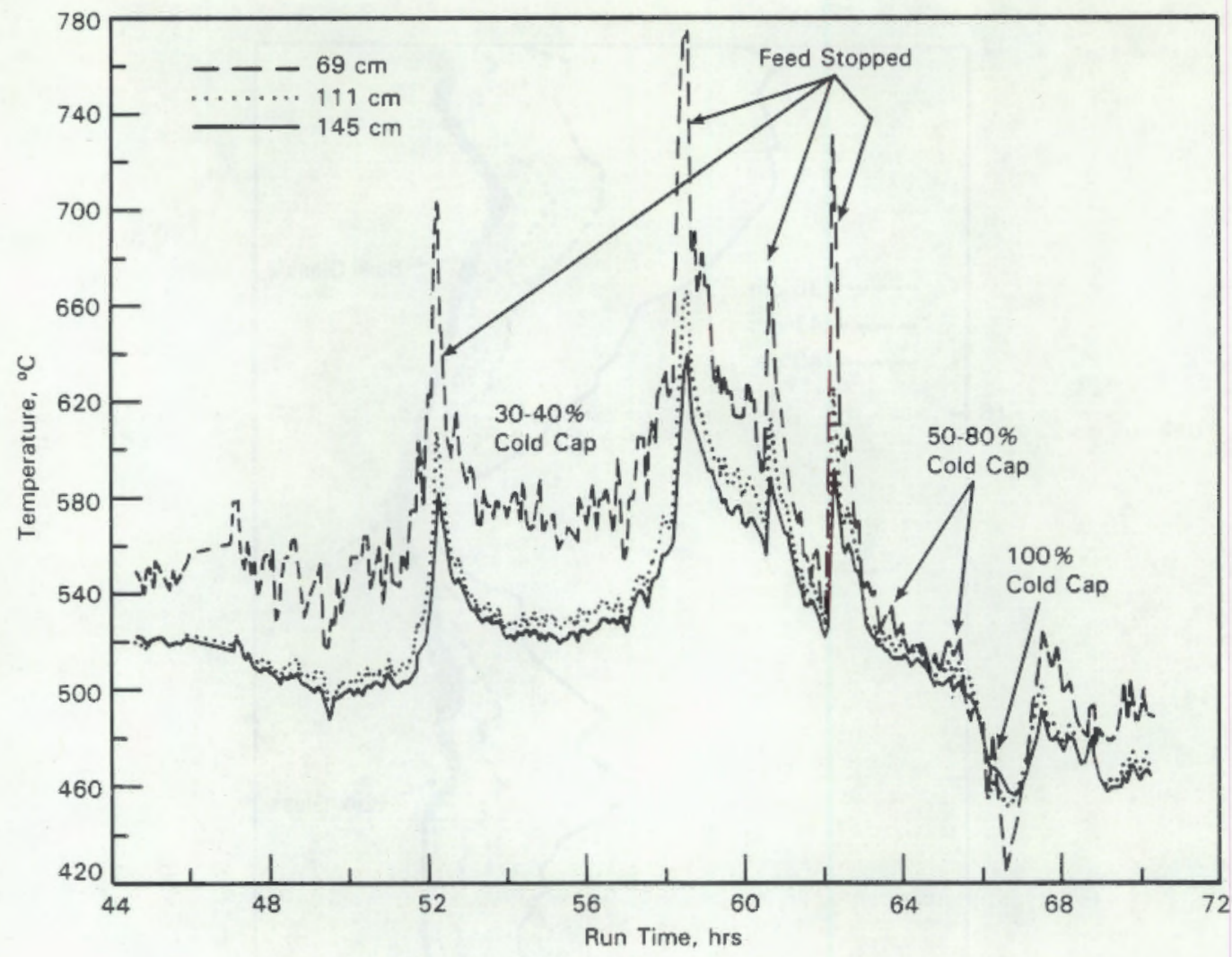

FIGURE 14. Plenum Temperatures, PSCM-16

radiation heat transfer from the melt surface, and it will be difficult to distinguish between incomplete cold cap coverage and venting through the cold cap.

OFF-GAS TEMPERATURES

Off-gas temperature data are difficult to correlate among the different runs due to the change from a side to top exit for the gases leaving the me1ter. PSCM-9 used the side exit from the melter, and the off-gas temperature "control" thermocouple was between the melter and the first scrubber. Off-gas temperatures were between 300 and $400^{\circ} \mathrm{C}$ and followed the same trends as the plenum temperatures. It is not clear whether or not this thermocouple was seeing thermal radiation from the melt surface.

PSCM-11 used a top exit to the off-gas treatment system. It is not documented if the off-gas temperature "control" thermocouple was moved to the new line. The thermocouple may have been attached to the outside of the new 
off-gas line. Off-gas temperatures were in the 100 to $200^{\circ} \mathrm{C}$ range and did not follow the trends shown by the plenum temperatures. As Figure 15 shows, this thermocouple responded well to feed stoppages and to venting of the melter.

\section{RECOMMENDATIONS}

The use of thermocouples for monitoring of the LFCM process and as input for operators to make process adjustments is well developed. Still to be determined is the optimum location within the melter cavity for these thermocouples. Recent experiments with the PSCM have shown that thermocouples clustered near the glass/cold cap interface can be used to detect foaming. Additional operating experience is needed to better understand the response of thermocouples placed in this configuration. Process control schemes using temperature feedback should be further developed and evaluated.

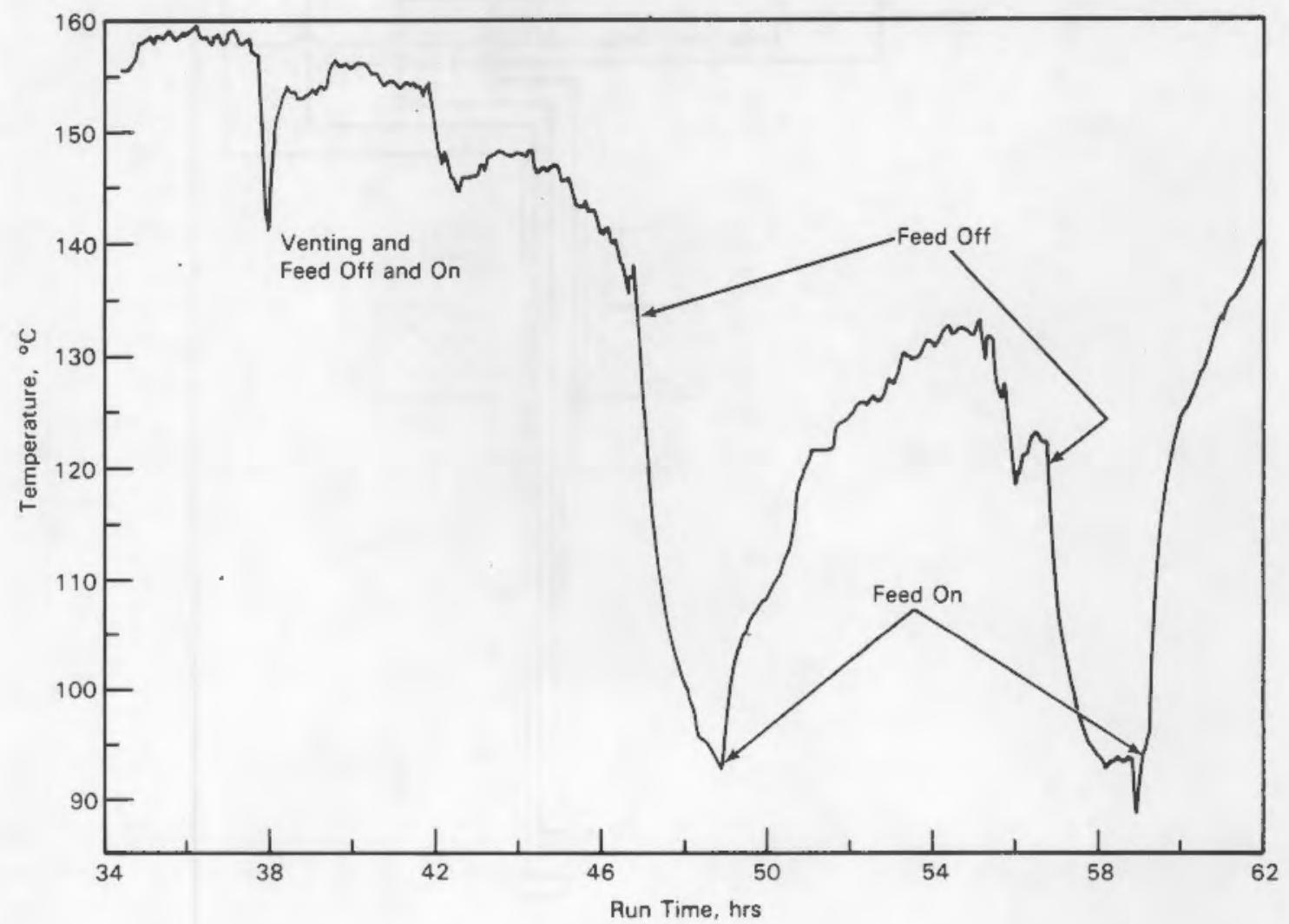

FIGURE 15. Off-Gas Temperatures, PSCM-11 
The pneumatic level detection system, or level bubbler, is designed to monitor glass level, specific gravity, stability of operation and to detect the presence of foam in the glass melter. The system developed at PNL (Figure 16) consists of an Inconel diptube, four purge air rotameters, four pressure transducers and appropriate chart recorders. The diptube was fabricated from $2.5-\mathrm{cm}$

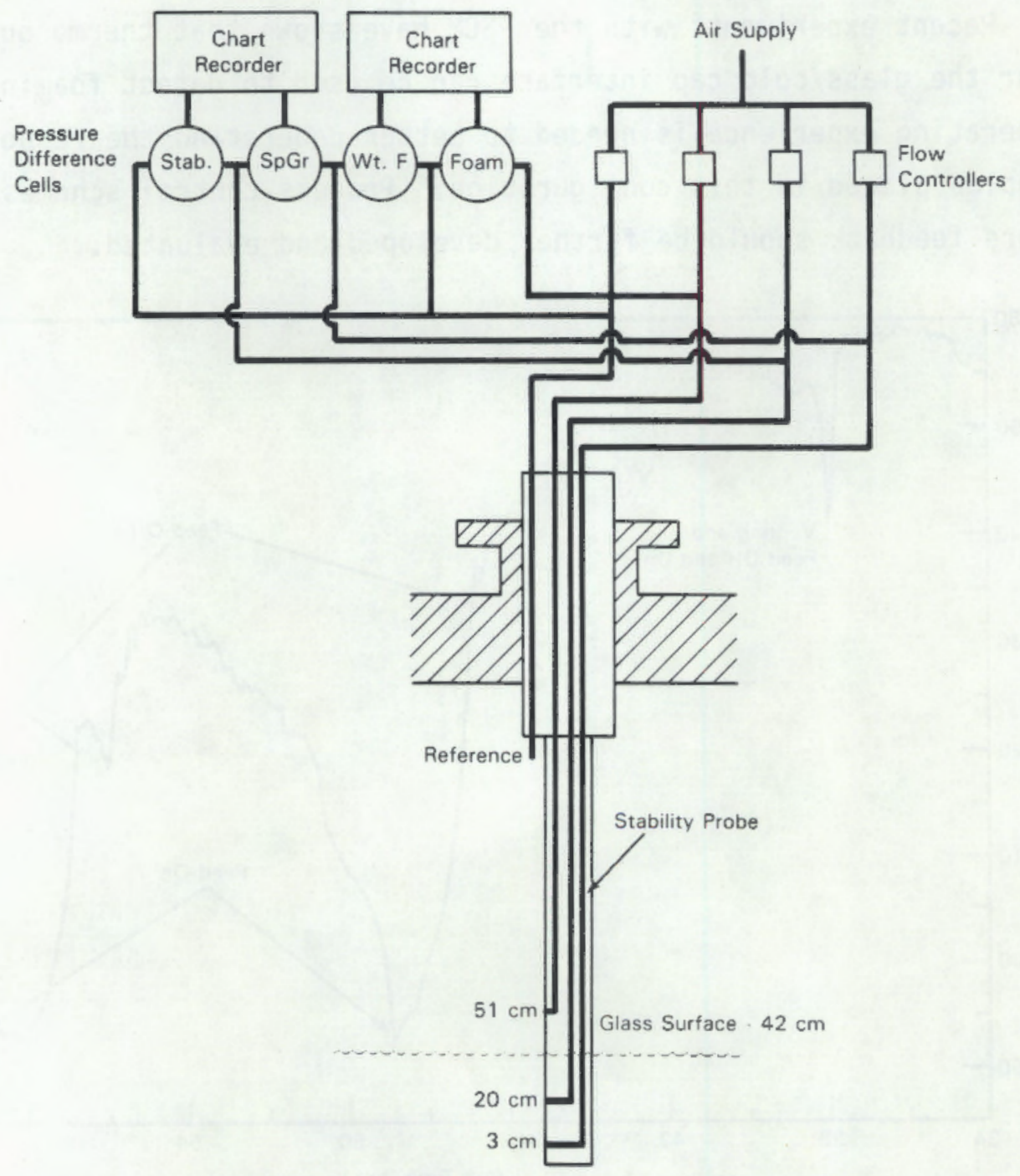

FIGURE 16. Glass Pneumatic Level Detection System Schematic 
Inconel round stock, which had three bore holes drilled lengthwise and was ported at the $2.5-\mathrm{cm}, 20-\mathrm{cm}$, and $51-\mathrm{cm}$ levels as measured from the melter floor.

During operation, air is purged into each borehole of the diptube and into the melter plenum at $1 \mathrm{SCFH}$. In the PNL system, the pressure transducers sense the pressure differences between the $2.5-\mathrm{cm}$ and $20-\mathrm{cm}$ levels, and between the 2.5-cm, 20-cm, 51-cm, and plenum reference. The pressure differences are recorded on a strip chart. The pressure difference between the $2.5-\mathrm{cm}$ and $20-\mathrm{cm}$ levels is used to determine glass specific gravity. A level difference of $17.5 \mathrm{~cm}$ was chosen rather than the traditional $25 \mathrm{~cm}$ to assure that the specific gravity measurement would still function when the melter glass level was as low as $25 \mathrm{~cm}$. The pressure difference between the $2.5-\mathrm{cm}$ and the plenum gives the weight factor. The melter glass level can then be calculated from the weight factor and the specific gravity. The pressure difference between the $20-\mathrm{cm}$ level and the plenum reference is used to indicate processing stabi1ity. This pressure difference gives essentially the same information as the weight factor measurement except the chart scale is expanded due to the lower total pressure difference with the stability measurement, making small fluctuations in the pressure more readily apparent. The pressure difference between the $51-\mathrm{cm}$ level and the plenum, defined as the foam detector, is normally zero, since both ports are above the glass surface. During melter foaming incidents, however, the foam rises and covers the $51-\mathrm{cm}$ port causing pressure-difference spikes, which are recorded on the strip chart.

Figure 17 shows a section of the strip. chart recorder with the stability and foam indicators for a period of normal melter operation. The sawtooth stability pattern of the line indicates glass level changes due to batch glass pours from the melter. The foam indicator line shows no unusual activity. Figure 18 shows the stability and foam indicators during a foaming incident. Note the series of spikes in the foam line and the depression in the stability line. The spikes in the foam indicator arise from having the foam above the $51-\mathrm{cm}$ port on the diptube. The depression in the stability line is probably due to the decreased resistance to flow of the purge air through the foamy surface relative to the melter glass. Occasionally, feed splatters on to the 


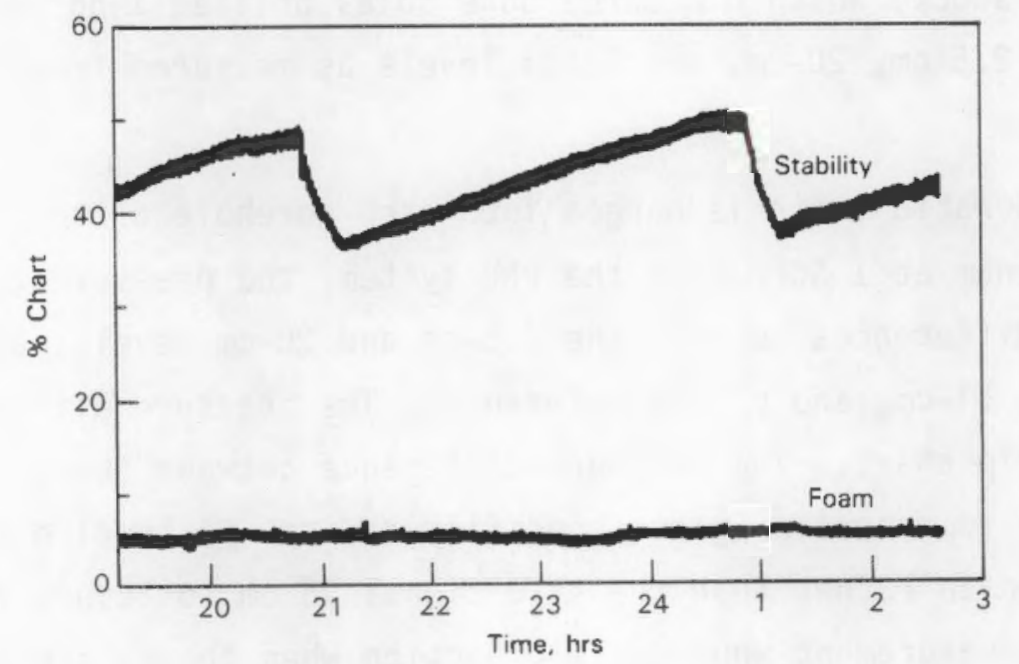

FIGURE 17. Strip Chart Segment Showing Stability and Foam Indicator Tracings During Normal Operation

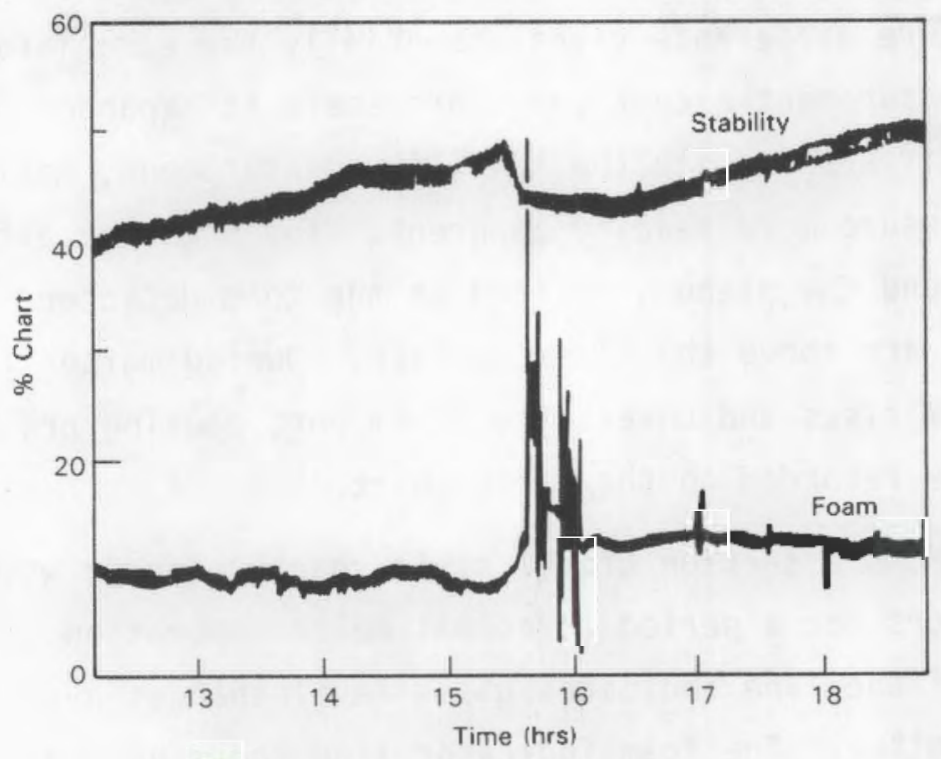

FIGURE 18. Stability and Foam Indicators During Foaming Incident

51-cm diptube port causing spike to appear on the chart, as shown in Figure 19. This can be distinguished from foaming because there is no depression in the stability line associated with it. 


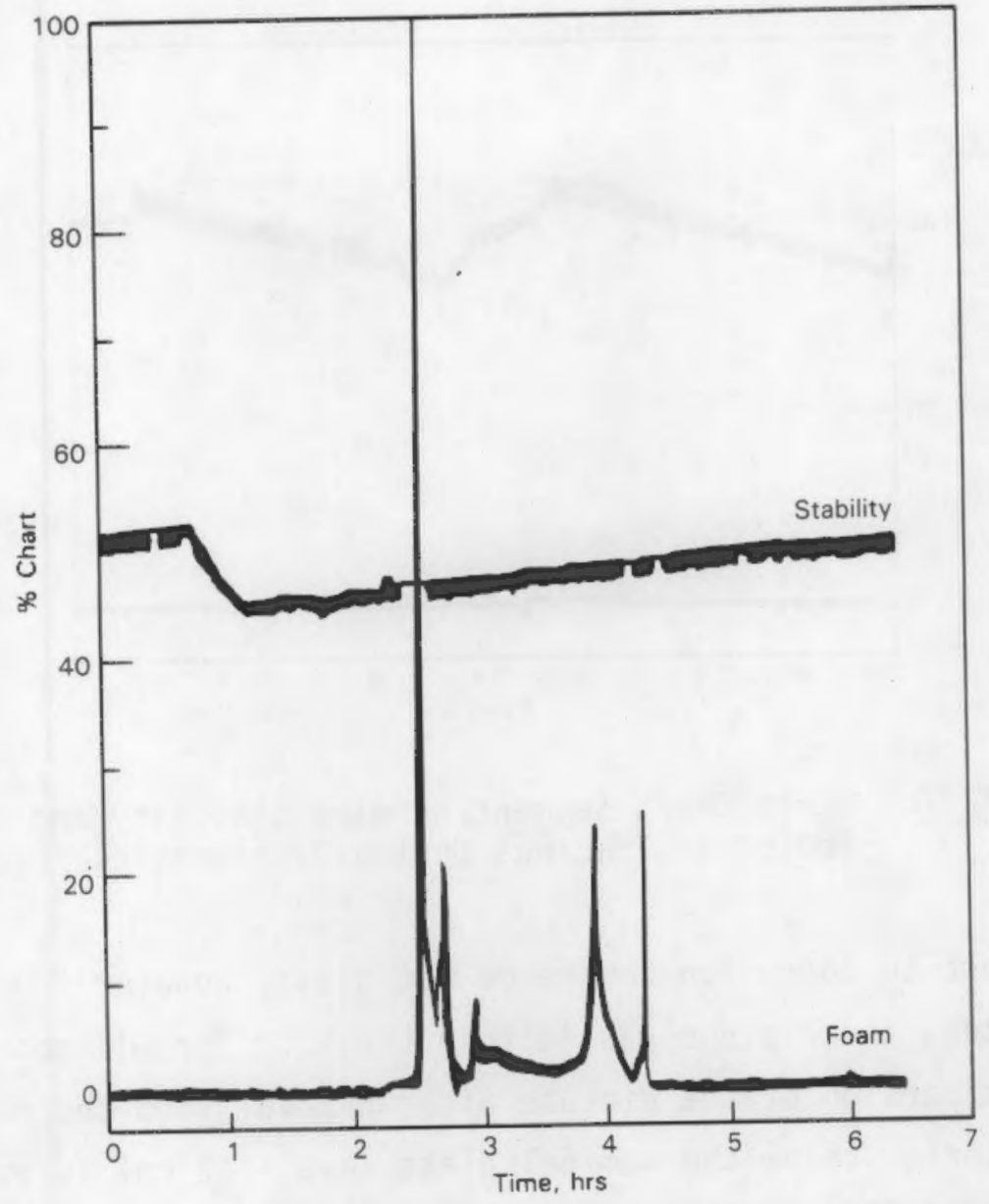

FIGURE 19. Stability and Foam Indicators Showing Spikes Due to Feed Splattering

Unstable operation, caused by significant overfeeding, results in a stability line that is jagged and wider, as shown in Figure 20. Changes in pressure under the cold cap are caused by accumulation and release of decomposition gases during periods of high-percentage cold cap coverage. These pressure changes, recorded by the stability sensor, result in a trace with many small peaks.

Reliability of the pneumatic level detection system is quite good because of the simplicity of the system and because all of the sensitive equipment is outside the melter environment. In radioactive operation, the only part of the system that needs to be in-cell is the diptube itself. The pressure transducers, rotameters, and chart recorders can all be located out of cell. The 


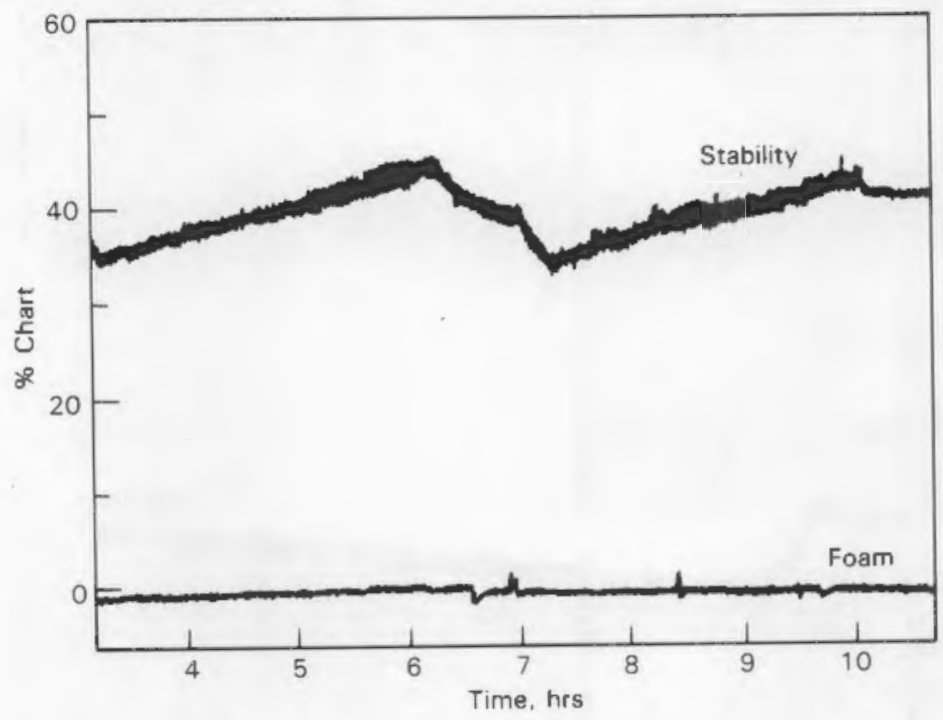

FIGURE 20. Strip Chart Segment Showing Stability and Foam Indicator Tracings During Overfeedings

diptube is subject to corrosion in the melter glass, however. During a recent test of the system, the diptube was left in the PSCM for 11 months. Figure 21 shows the bottom portion of the diptube after removal from the melter. A general loss of material below the nominal glass level $(42 \mathrm{~cm})$ is evident in the photograph. Figure 22 shows the $51-\mathrm{cm}$ port, which is used for the foam detector. This port, which is normally above the glass surface, is essentially in original condition. Figures 23 and 24 show the $20-\mathrm{cm}$ and $2.5-\mathrm{cm}$ level ports, respectively. These ports have been eroded, thus changing the effective level of the port. This led to erroneous specific gravity and level indicators. The erosion of the ports could be minimized by a minor modification to the diptube design. This would involve putting a nozzle at each port so that the bubbles are released away from the side of the diptube.

\section{RECOMMENDATIONS}

Tests of diptubes designed to minimize erosion at the ports and general corrosion should be conducted. Air flow rates to the diptube need to be optimized. Additional operating experience is needed to better understand and interpret the bubbler indications. 


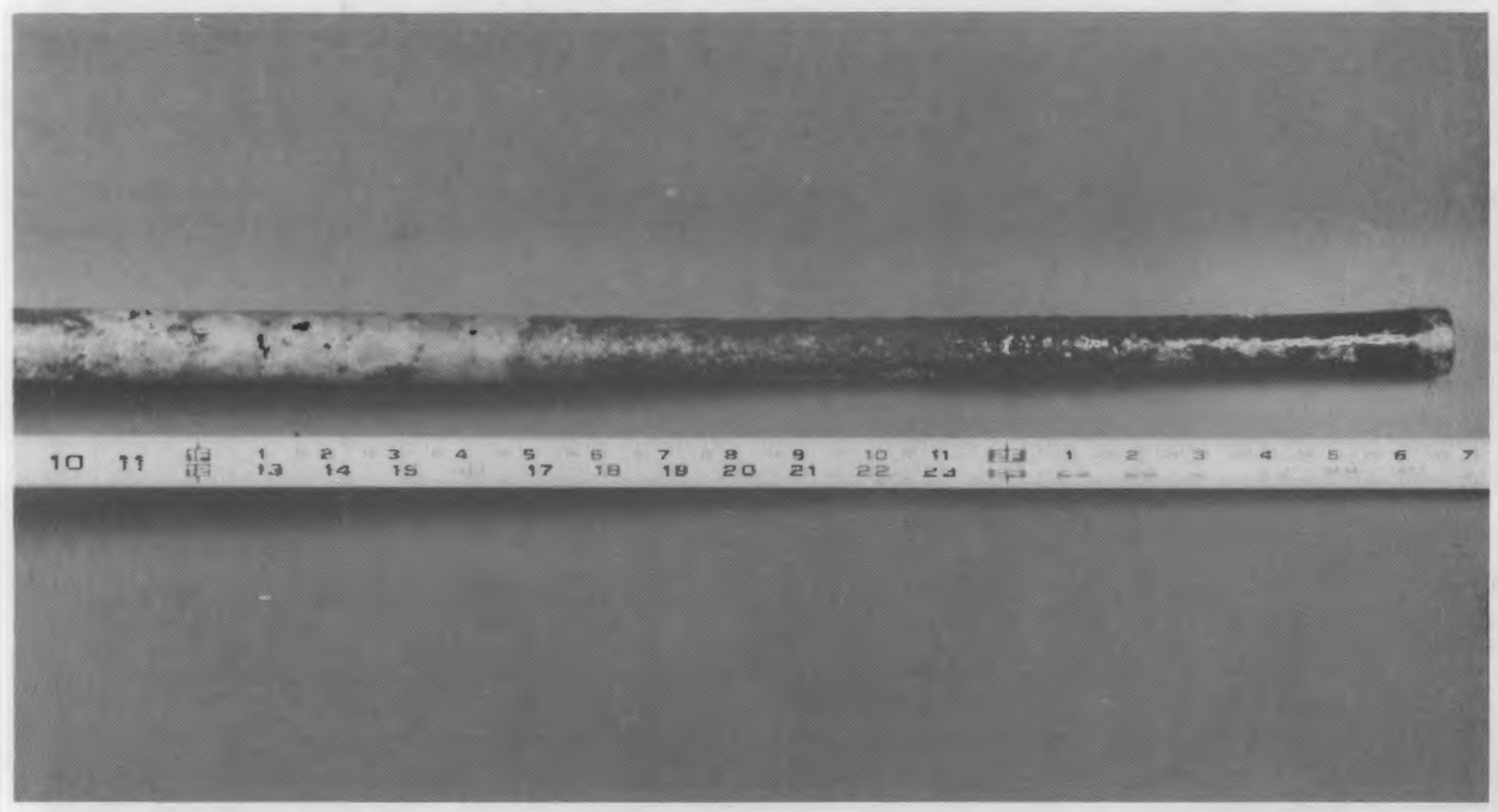

FIGURE 21. Level Bubbler Diptube After PSCM-21

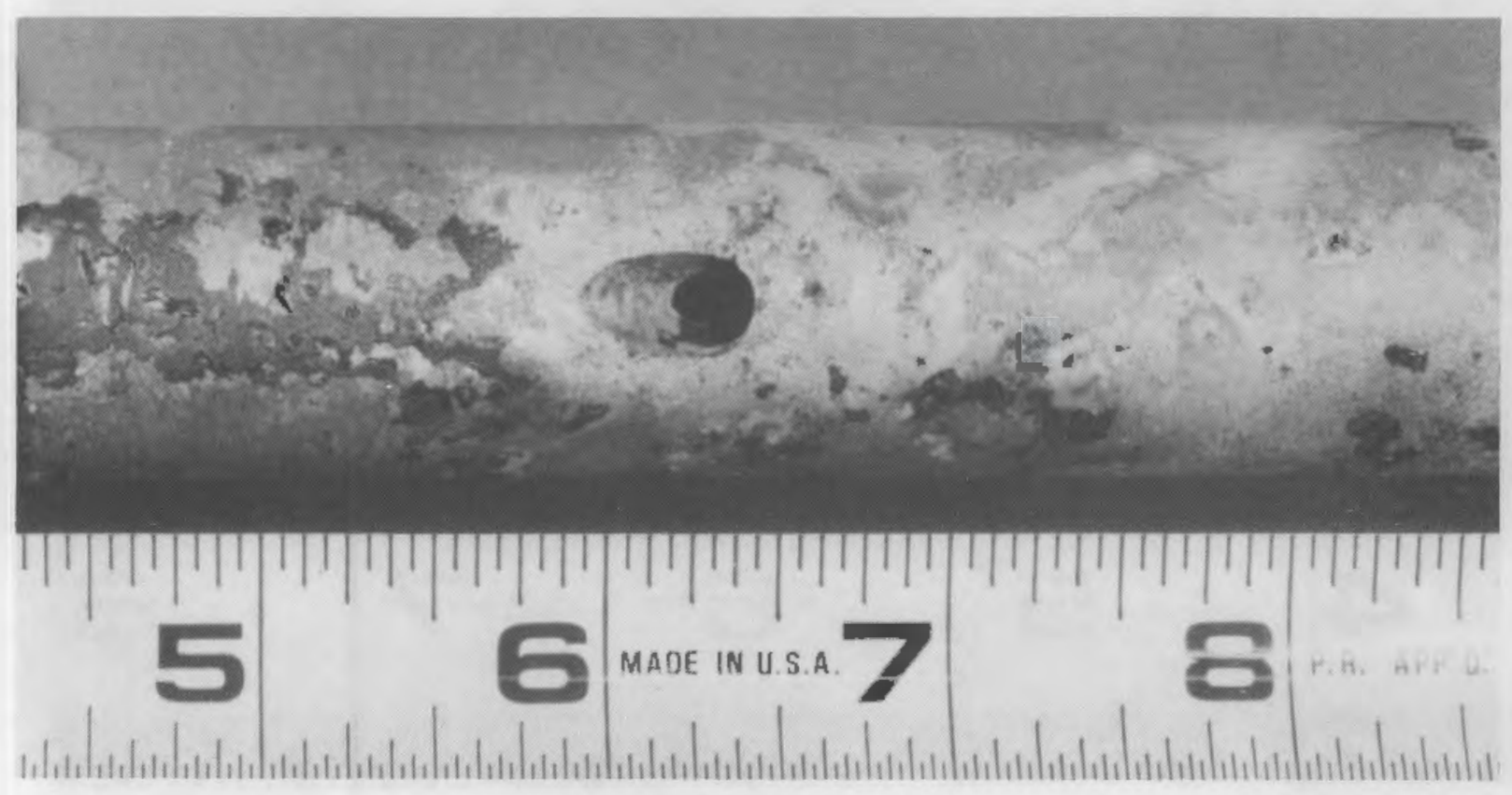

FIGURE 22. Level Bubbler Diptube 51-cm Level Port After PSCM-21 


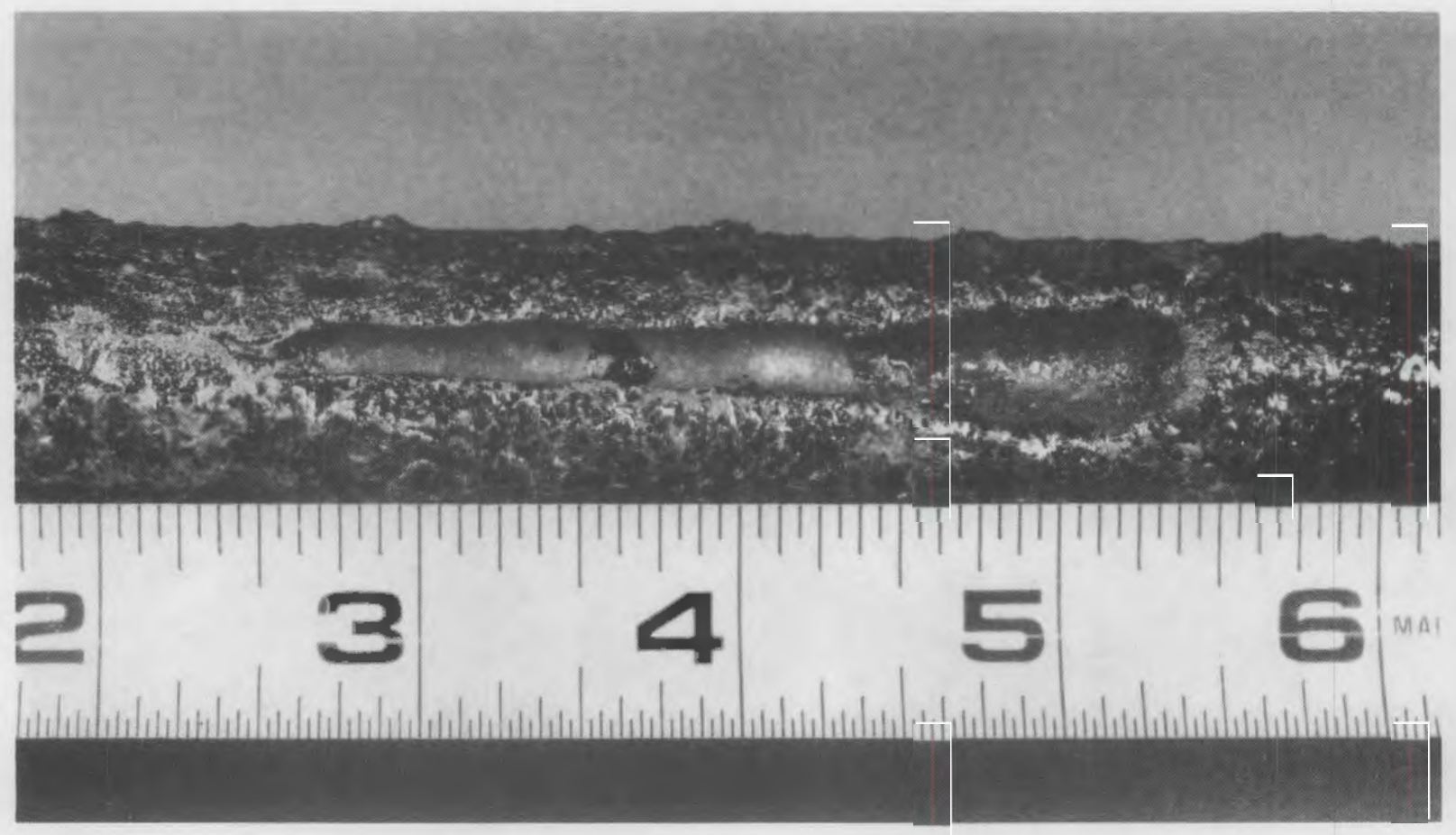

FIGURE 23. Level Bubbler Diptube 20-cm Level Port After PSCM-21

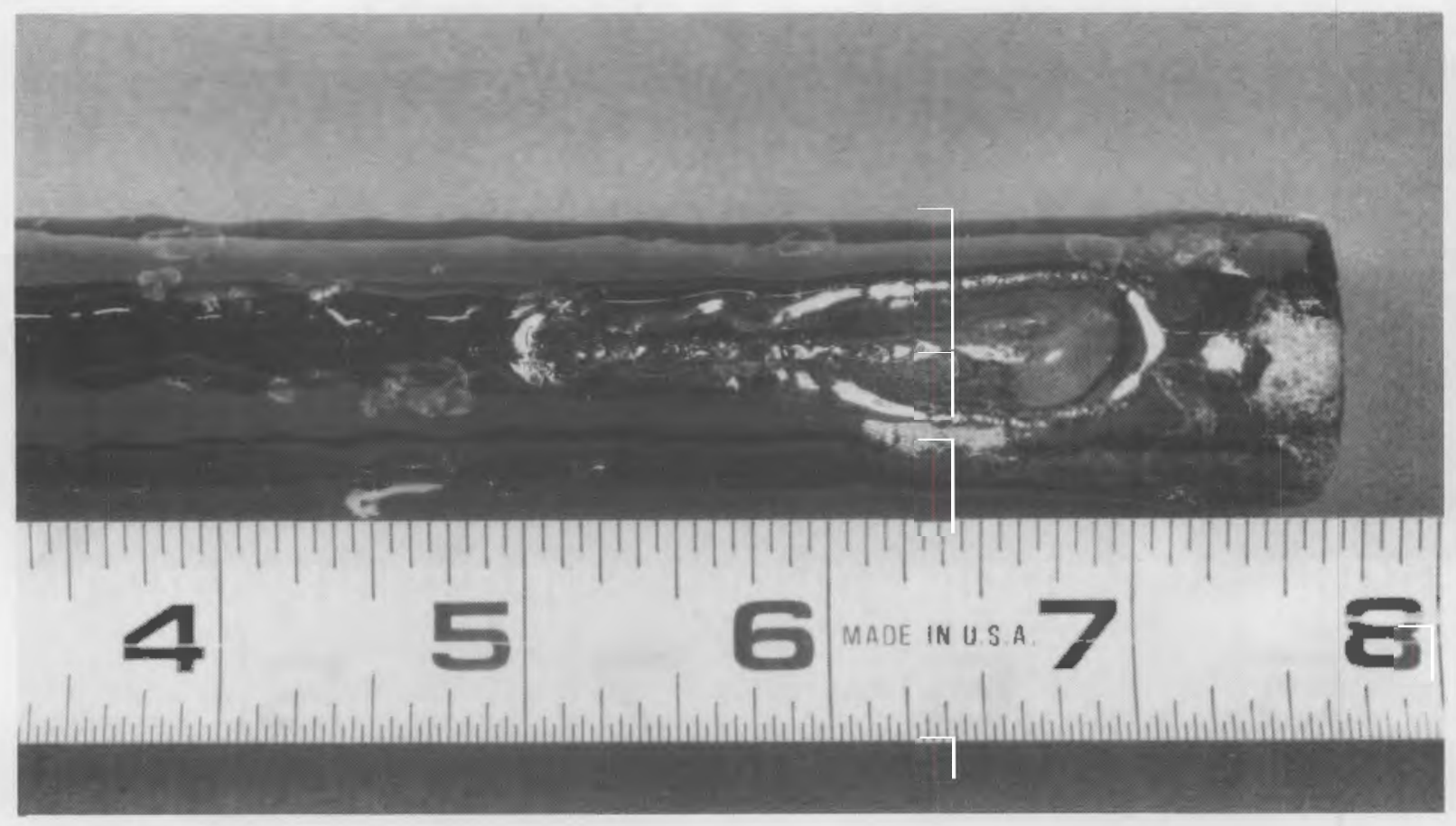

FIGURE 24. Level Bubbler Diptube 2.5-cm Level Port After PSCM-21 


\section{MELTER VIEWING SYSTEM}

Operators of the PSCM use direct visual observation of the glass/cold cap surface to estimate the extent of cold cap coverage, to check for overfeeding and/or foaming, and to determine the physical condition of the melter refractories, electrodes, and instrumentation. In remote environments, direct observation will not be feasible. Therefore, the melter viewing system is being developed to provide a remote set of eyes for looking into the melter.

\section{EQUIPMENT DESCRIPTION}

The melter viewing system is a high-resolution video camera and associated optics for looking down from the roof of the melter onto the glass/cold cap surface. The current camera design is shown in Figure 25. The camera itself is located outside the melter where additional shielding can be provided. Tests at Savannah River Laboratory (SRL) have shown that the camera will survive cumulative gamma doses in excess of $5 \times 10^{7}$ rads (Heckendorn 1983).

Early PNL melter viewing systems based on the visible light spectrum did not function well because of the low light levels in the melter. In the current design, a filter in the optical path removes light with wavelengths less than $0.7 \mu \mathrm{m}$, including most of the visible light, such that the camera monitors the infrared spectrum in the melter. The resulting infrared image can be directly related to the temperature and emissivity of the glass/cold cap surface and other internal melter features. The gray-scale video image is of a high quality suitable for observing the cold cap condition.

Electronics that would be located outside the radioactive processing cell include the camera controller, a color encoder, gray-scale converter, color and black-and-white monitors and a video tape unit. The gray-scale converter can be calibrated to indicate temperatures and areas of features inside the melter. This information can be used by the operators to estimate the size of the cold cap.

The camera's close proximity to the hot melter requires that cooling be provided. One air circuit flows past the camera itself and then down the optical path to the mirrors and lenses before exhausting outside the melter. A 


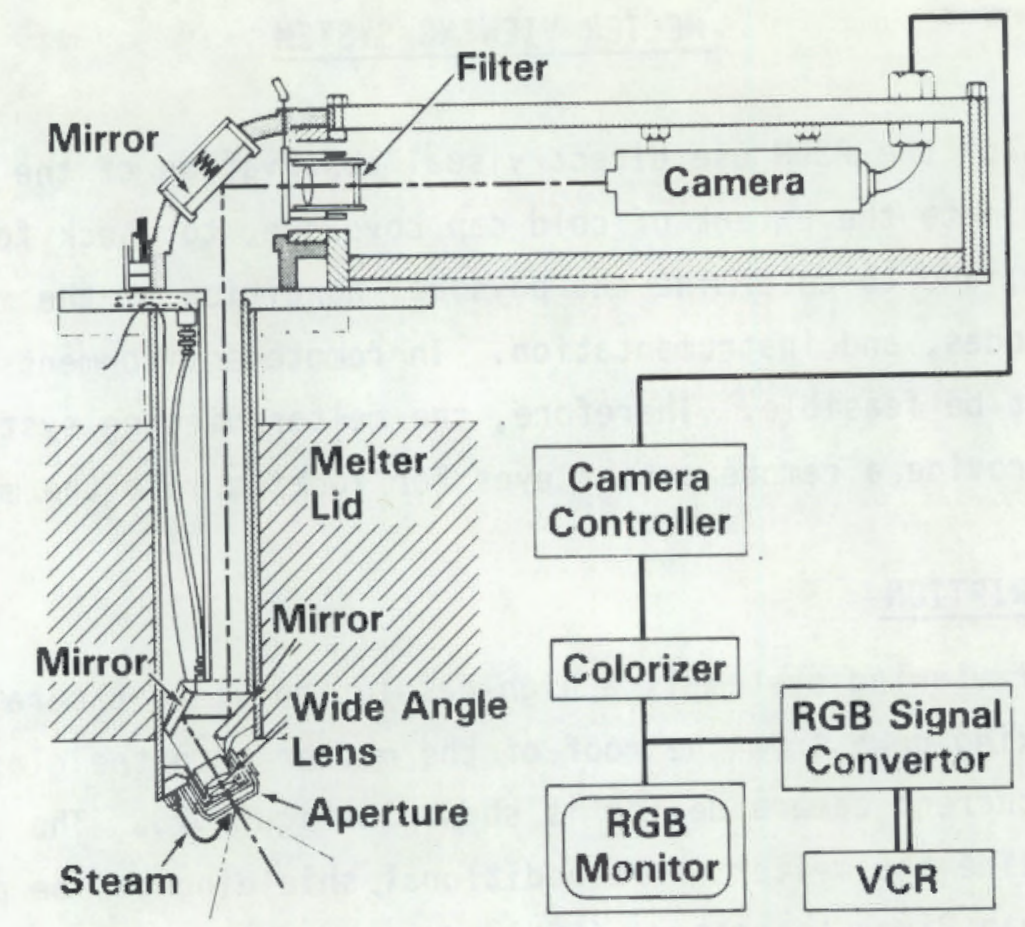

FIGURE 25. Melter Imaging System

second circuit using 2 SCFM air flows past the lenses, through the aperture, and into the melter plenum. This limits the airflow into the melter and prevents particulates from entering the aperture and blocking the field of view. Temperatures in the region of the mirrors and lenses range from 70 to $130^{\circ} \mathrm{C}$ with a cold cap present to greater than $250^{\circ} \mathrm{C}$ with no cold cap. The cooling causes some condensation on those parts of the camera that extend into the melter plenum. A steam jet periodically directed at the lens aperture has proved successful for removing condensate that obscures the aperture. Some of the condensates are corrosive and have caused the failure of the aperture piece.

\section{INITIAL PERFORMANCE CHARACTERIZATION}

Testing of the IR camera has been limited to an evaluation of the visual picture and has not included using the gray-scale converter to estimate cold cap size. The camera has been installed in the north rectangular port on the PSCM and has pointed at either the southwest or northeast corner of the melt surface. The northeast corner is also visible from the viewport on the PSCM but the southwest corner is not visible except with the camera. When looking 
at the southwest corner, more than a quarter of the melt surface was visible; the melter walls and the south electrode filled the rest of the field of view. The feed nozzle, thermowell and bubbler probe were easily recognized. Feed could be seen pouring into the melter surface, and cold cap characteristics including boiling feed, crust and open vents were easily identified. From the combined perspectives of the viewport and the camera, growth, regression, and drifting of the cold cap could be observed. It is necessary to see the entire melt surface to distinguish between growth/regression and drifting of the cold cap.

There are some problems with the current camera design. First, the mirrors and lenses within the boundary of the melter plenum can be exposed to temperatures greater than $250^{\circ} \mathrm{C}$, even with the air cooling. Thermal cycling associated with the idling and feeding can cause damage to these components requiring removal of the camera and significant labor time to make repairs. Cooling of the lenses causes condensation on the camera housing, which has resulted in destructive corrosion of the housing itself. Second, the $L$ shape of the periscope and camera housing limits the placement of the camera on the melter among the other instrumentation, feed line, off-gas line, etc. that must share the space above the melter. Third, the current design and location of the camera does not permit viewing the entire melter surface so some information about the cold cap is unavailable. Looking down onto the melter surface rather than across the surface, as can be done from the viewport, may preclude visual detection of foaming or third phase formation. These are not insurmountable problems and the IR camera is an important component of the instrumentation package for the remote glass melter.

\section{RECOMMENDATIONS}

Testing of the melter viewing system is in its infancy. Additional operating experience is needed to appreciate the capabilities and limitations of the camera and to be able to interpret the images that the camera provides. Design problems including cooling for the viewing system and obtaining images of the entire glass/cold cap surface need to be resolved. 
ACOUSTIC MONITORING SYSTEM

The acoustic monitoring system is being evaluated to determine its sensitivity to acoustic emissions from the melter due to overfeeding, foaming, and/or feed stoppage. Early experiments in the program established that the system can detect changes in melter acoustic activity. Later experiments were conducted to correlate changes in acoustic activity to changes in melter operation.

In the simplest terms, the acoustic monitoring system can be thought of as a listening device that detects and counts discrete sounds, measures their amplitudes, and then records the quantity and amplitude of the sounds. During melter operation, we expect the amplitude and quantity of acoustic events to vary in accordance with changes in the operating conditions. Process activities that should cause differences in the quantity and amplitude of acoustic signals include the formation and breaking of bubbles during foaming, cold cap formation during overfeeding, and the slurry striking the melt or not during feeding or feed blockage.

\section{EQUIPMENT DESCRIPTION}

The instrument used in the acoustic monitoring experiments is an acoustic emission pipe monitoring system, that was originally developed at PNL for detecting crack growth and leaks in pipes. It is a microprocessor-based system that counts and digitally records very low amplitude, discrete acoustic events and also periodically calculates and records the RMS amplitude of acoustic activity. The system is packaged in a portable, shock-mounted fiberglass cabinet with everything except the sensors and preamplifiers captive within the cabinet. Figure 26 is a photograph and Figure 27 shows a block diagram of the acoustic monitoring system. A less sophisticated instrument system would be effective in acoustic signature monitoring once the key parameters are identified. This system was used in the current work because it includes the needed capability and was available. 

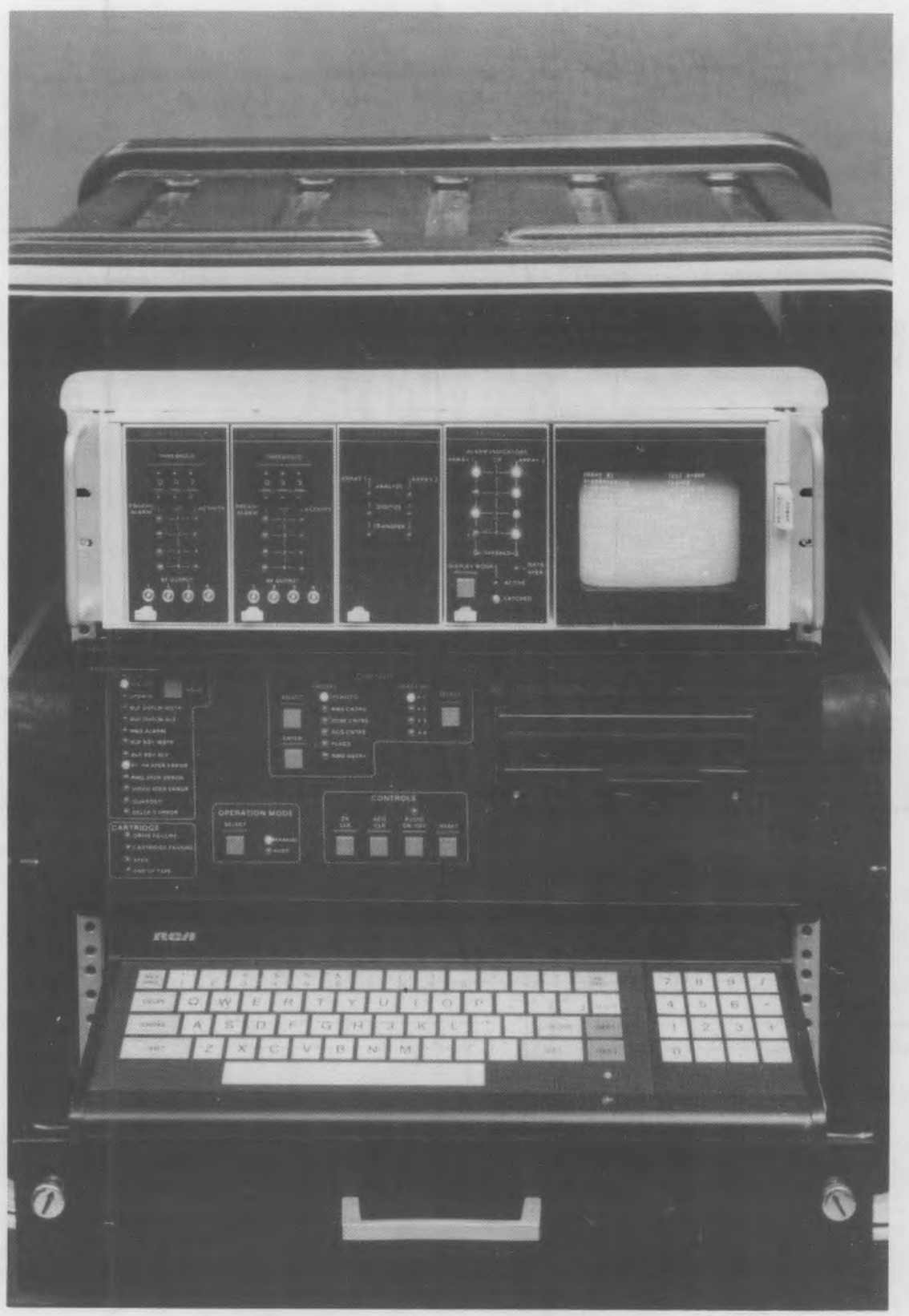

FIGURE 26. Acoustic Emission Pipe Monitor

In the acoustic monitoring system, piezoelectric sensors are used to convert acoustic energy in the melter into an electrical signal for analysis. A sensor, which can be thought of as a specialized microphone, contains a disc of piezoelectric material that emits electrical energy when it is physically stressed by mechanical energy such as sound. Preamplifiers and filters are 


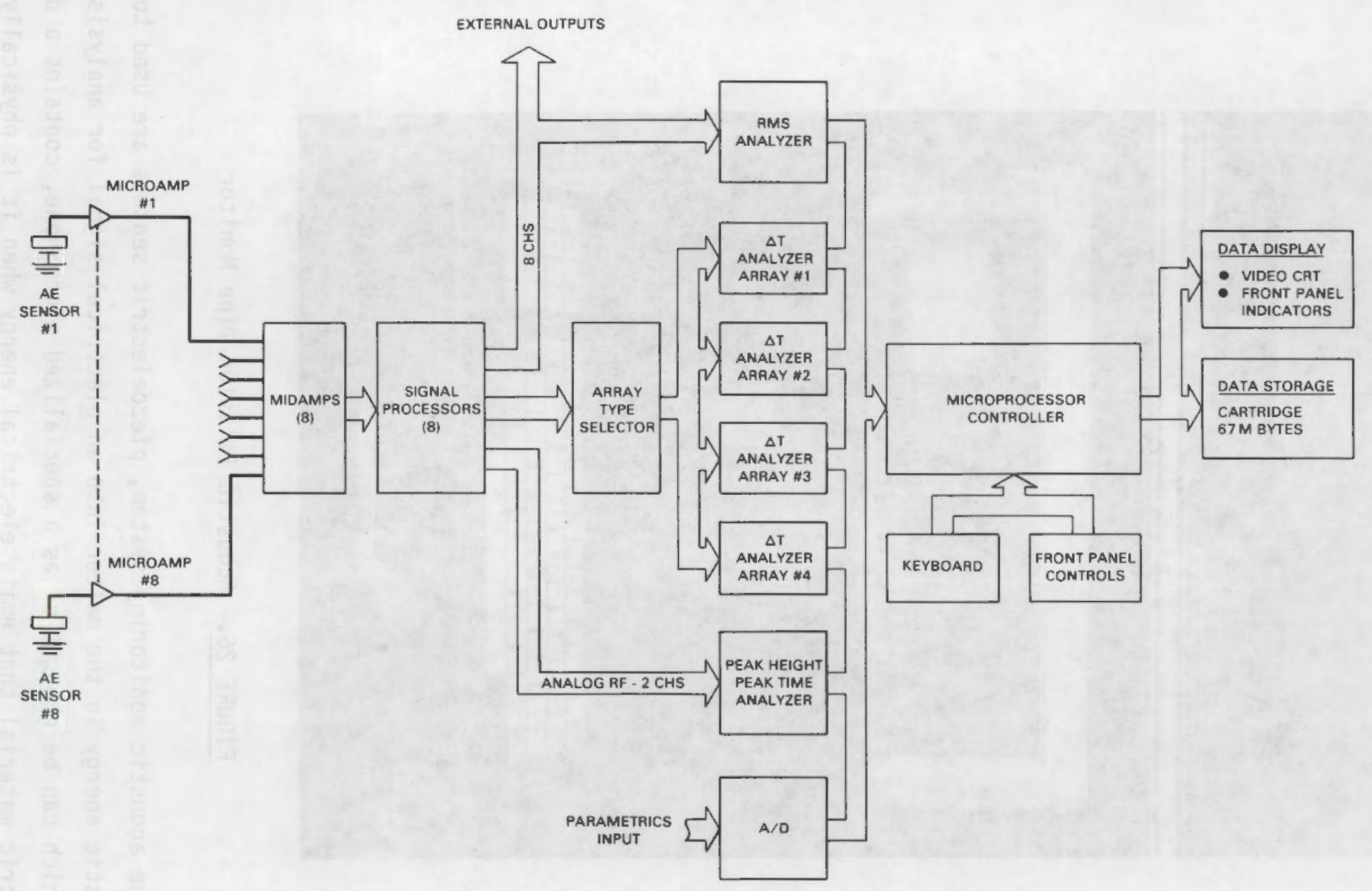

FIGURE 27. Functional Block Diagram of AE Pipe Monitor 
connected between the sensors and the instrument as required to assure that an adequate signal is input to the instrument. The acoustic system operates at frequencies well above the audible range and detects signals with very small amplitudes compared to those detectable by ear. The system can monitor continuousiy and respond objectively to any acoustic changes.

Because sensors won't survive inside the melter environment, waveguides are used to conduct acoustic energy from the melter to the sensors. These waveguides consist of Inconel rods that are inserted through the melter housing and into the molten glass. The sensors are attached to the exposed waveguide ends using epoxy with an insulating wafer of aluminum oxide between the rod and sensor to electrically isolate the acoustic monitoring system from the melter. A series of preamps and filters are connected in the line between the sensor and instrument as required.

During PSCM-20, only one waveguide was used, and it penetrated the top of the melter and extended straight down through the cold cap and into the melt. We were concerned that perhaps rubbing of the cold cap against the waveguide was causing spurious signals to be recorded as the level in the melter varied. For PSCM-21, a second waveguide was inserted into the riser glass through the airlift tube so that it could not come in contact with the cold cap.

In order to demonstrate that an acoustic emission system would be appropriate to use as a melter monitoring system, a simple experiment was run. In the experiment, an actual melter waveguide and transducer assembly was inserted into a beaker of water on a hot plate. The water was slowly heated until it boiled. The acoustic system readily detected the initiation of boiling. We concluded from this experiment that the waveguide-coupled acoustic system is sensitive to acoustic events that occur in a contained volume of liquid.

\section{INITIAL PERFORMANCE CHARACTERIZATION}

The acoustic monitor data for PSCM-20 and PSCM-21 were collected and stored in digital form on magnetic tape. Each acoustic event recorded by the system is assigned a serial event number. During PSCM-20, over 750,000 events were recorded, while PSCM-21 had more than triple that amount. For each event, 
the time, amplitude, rise time, RMS threshold level, and RMS amplitude was recorded. Events exceeding the RMS threshold level caused the system to calculate and record the RMS amplitude of the signals that immediately follow.

Plots of the recorded data were made for periods of interest (known foaming, overfeeding, or feed stoppage) during PSCM-21. Figure 28 shows a typical graph from PSCM-21 covering the time period from approximately 10:24 to 12:11 on $6 / 8 / 85$. This graph is made up of 14,395 events detected by the sensor installed in the airlift tube. The horizontal axis represents time in minutes and the vertical axis is cumulative events during the period so that the graph represents a "time profile" of acoustic activity. Changes in melter acoustic characteristics are reflected on the graphs as changes in slope. A steeper slope represents an increase in the rate of acoustic events.

In interpreting the data, the objective is to correlate changes in acoustic events with changes in melter operating parameters as they were recorded in the melter logbooks. It was hypothesized that process changes such as overfeeding, foaming, and feed stoppage would cause distinct changes in the acoustic behavior of the melter. This hypothesis was based on melter operators hearing different sounds as the melter process varied during earlier experiments. Two types of acoustic data were recorded by the system: quantity (or rate) and amplitude. The plots of quantity versus time result in a time profile of acoustic events, while plots of amplitude versus time show how the RMS amplitudes of acoustic signals vary with time. No significant interpretation of the RMS amplitude plots was possible due to factors described later in this report. It is recognized that the off-line data interpretation method used during these feasibility experiments is inadequate for process control. A real-time method of interpretation will be required if acoustic monitoring is to be used as a process control tool for melter operation. 


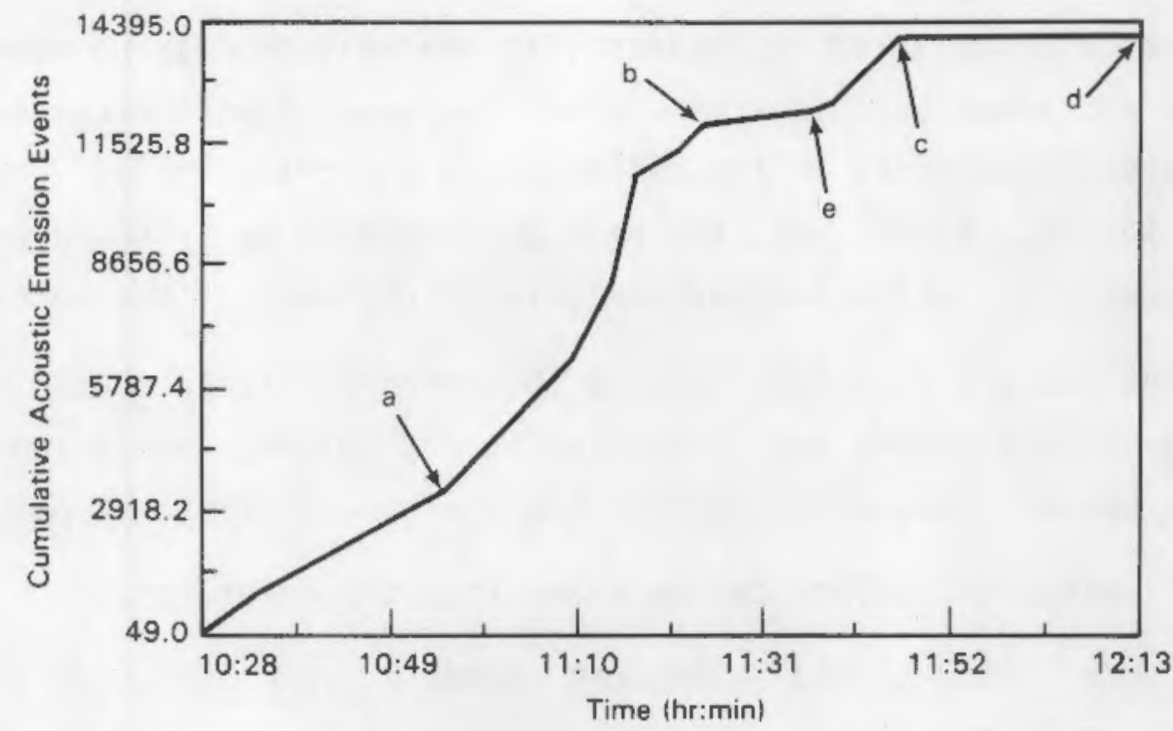

FIGURE 28. Typical Graph Showing Cumulative Acoustic Events During a 105-Minute Period of PSCM-21

Referring again to Figure 28 , several changes in event rate are indicated by changes in slope. During the period shown in the graph, the following changes occurred in melter operation: at about 10:56 the feed line plugged, foaming in the melter was observed at 11:20, the feed nozzle was flushed at 11:24 and the feed was restarted, at 11:48 the feed and power were shut off, and the power was turned back on at 12:13. Also during this period, an air lift was being carried out from 10:36 to 11:45. Point (c) corresponds to the power being shut off and point (d) is when the power was turned on. Point (b) is when the nozzle was flushed and the feed was restarted. The nozzle initially plugged in the vicinity of point (a).

The flat area between (c) and (d) represents the period when power to the electrodes was shut off. This pattern was observed throughout the run whenever power was cycled. While it is encouraging that the acoustic monitoring system is consistently sensitive to this process change, it is also observed that the signal detected from the power cycles is of much greater amplitude than the other events detected. Because power cycling is such a large signal and not 
one of the process variables of interest, it may well be masking more pertinent data. It is not known at this time whether the power events recorded were caused by acoustic activity in the melter or by electrical noise generated while power was on. Either way, the data can probably be filtered to eliminate the power signals and allow further analysis of the data of interest.

The slope changes at points (a) and (b) are most likely caused by the nozzle plugging and unplugging and/or foaming in the melter. No reason could be found in the melter logbooks to explain the increase in slope at point (e).

The following conclusions can be drawn from these results.

- Melter power being turned on and off showed a clear effect on the acoustic activity. It is not known whether these are actual acoustic events or the results of electrical noise. Regardless of the source of these events, they are large enough in signal density to possibly mask signals of interest such as foaming, over feeding, and feed stoppage.

- Even with the melter power at steady state, changes in the slope of the time profile of acoustic data were observed. These changes correlate with process changes such as foaming and feed stoppage.

- No conclusions can be drawn regarding acoustic event rate and over feeding. Over feeding is such a slowly occurring process that it does not show up on the time profile graphs. It was expected that over feeding and cold cap formation would be reflected in the RMS amplitude of the events, but the power on/off signals dominate the RMS data.

\section{RECOMMENDATIONS}

Based on the results of the limited experiments carried out on acoustic monitoring during FY85, the following recommendations are made.

- Further analysis of the acoustic data from PSCM-21 is required. This further analysis would begin by filtering out the large amplitude 
signals caused by melter power cycling. With the power signals eliminated, the RMS amplitude data can be more readily graphed and analyzed.

- Contingent upon achieving good results from the work described above, a more thorough acoustic monitoring experiment should be carried out. This experiment would allow correlations between process changes and acoustic events to be quantified, which would form the basis for using acoustic monitoring as a process control tool. 


\section{TIME-DOMAIN REFLECTOMETER LIQUID-LEVEL DETECTION SYSTEM}

A time-domain reflectometer (TDR) liquid-level monitoring system is under development for remote melters and liquid storage tanks. Dip tubes are frequently used for this purpose, but erosion and corrosion of these devices cause the indicated level to drift from the actual position. The TDR electronic system is expected to be less sensitive to corrosion-induced drift and may be capable of detecting foam accumulation and phase separation at the glass surface in the glass melter. Initial tests with the TDR have been plagued with problems with the electronics, precluding completing the evaluation of the instrument.

\section{EQUIPMENT AND OPERATION DESCRIPTION}

The TDR liquid-level detection system relies on the principle that a step voltage change input to an RF transmission line is transmitted down the line at the speed of light. If an electrical discontinuity such as a short circuit across conductors is encountered, a reflected wave front is generated at that point and propagates back along the transmission line, also at the speed of light. Therefore, the time from signal injection to reflected signal return is a direct measure of the round-trip path length to the short circuit. Conducting liquids including aqueous slurries and molten glass can provide such a short circuit.

The TDR uses two parallel Inconel 690 bars connected at the base as the working portion of the transmission line. This probe is suspended vertically through the top of the melter via a standard pipe flange. The rods are electrically isolated from their supporting mount by a 3.2-cm thick ceramic spacer and by 1500-volt ceramic blocking capacitors located in the probe head. A coaxial cable connects the probe with its associated electronics. Technology Dynamics, Inc. (TDI), of Woodinville, Washington, assembled the electronics including a Tektronics 1502 Time Domain Reflectometer for measuring distance and impedance and a STD bus single-card computer for overall system control. Output from the TDR includes a graphical and numeric display of the liquid level and a CRT display of the impedance along the working region of the 
probe. Resolution of the TDR is estimated to be 0.2 inches. The impedance curves can be used to characterize conditions at the liquid surface including foaming or the presence of a second phase. If only a thin layer of foam or salt is present on the glass surface, the TDR is not expected to reliably recognize the material but will indicate a glass level slightly higher than the actual glass level.

\section{INITIAL PERFORMANCE CHARACTERIZATION}

Prior to evaluating the TDR during operation of the PSCM, tests were conducted to determine the ability of the TDR system to measure the liquid level in a slurry holding tank and in an idling melter. The response of the TDR to glass foam was also characterized.

The impedance output from the TOR system for various slurry depths is shown in Figure 29. This family of curves was generated by increasing the slurry level and periodically recording the TDR output. The parallel nature of

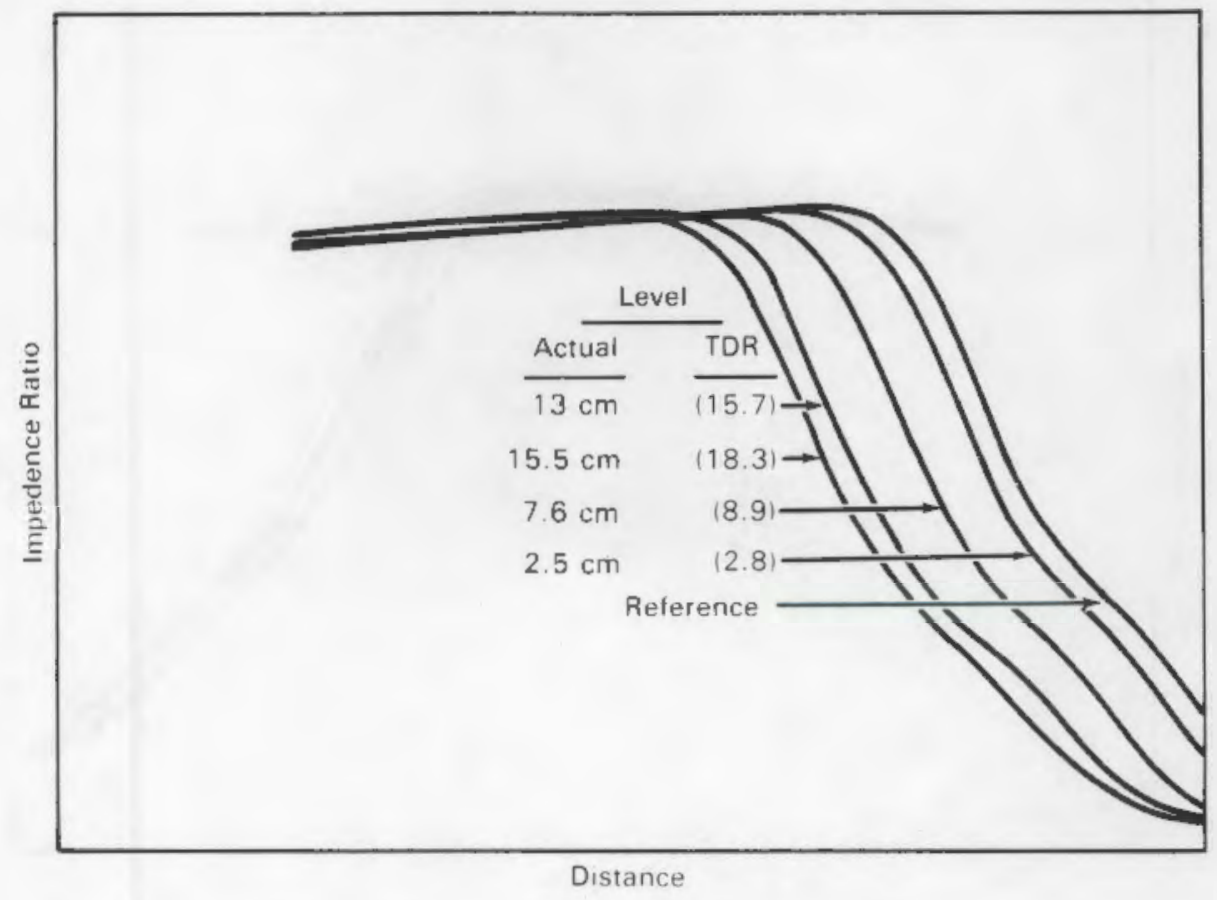

FIGURE 29. Impedance Ratio Traces Showing Increasing Slurry Level 
the curves indicates that the slurry/air interface was well defined with no foam or other phases accumulating at the interface.

The slurry levels indicated by the TDR were nearly $20 \%$ higher than the actual levels. This error was consistent throughout the tests and is believed to be a span-related calibration error that is user adjustable. Similar results were obtained for measured glass levels in the High-Bay Ceramic Melter $(\mathrm{HBCM})$, although the error was only about $10 \%$.

The response of the TDR to glass foam was investigated by inducing reboil in the HBCM. Figure 30 shows the impedance curves recorded for this test. The curves are not parallel as observed for the slurry-level tests but begin decreasing at shorter distances along the probe as the foam height increases. This corresponds to the lower conductance of the foam relative to the glass, resulting in a lower energy reflection and a less well defined impedance curve.

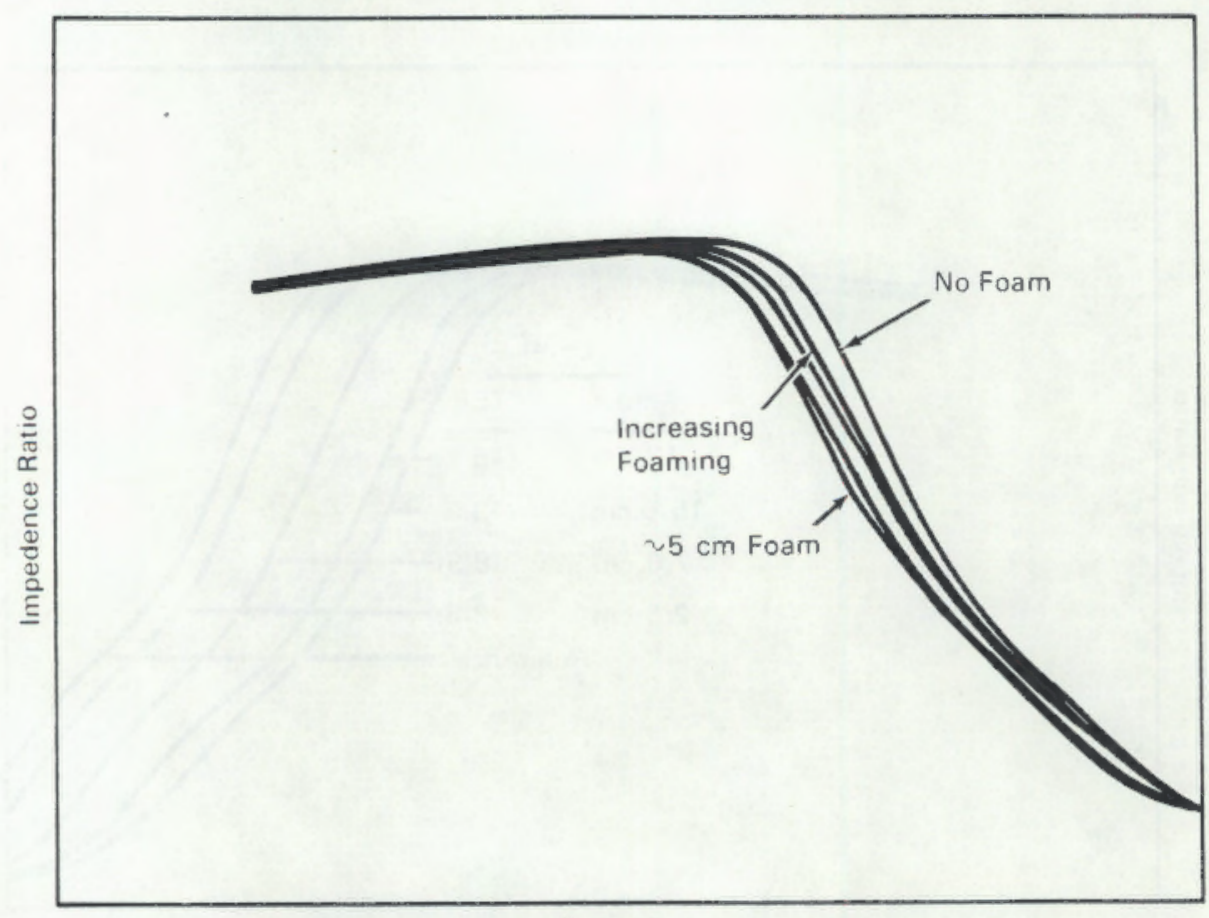

Distance

FIGURE 30. Response of TDR System to Glass Foam 
Initial testing of the T.DR system in the PSCM identified signal drift, electrical noise in the melter, and problems related to cold cap obstruction. Drift of the indicated glass level was caused by humidity-related changes in the TDR timing circuits. The timers are resistor/capacitor circuits using very large resistances. The actual resistance of the resistors was found to be a function of the ambient humidity. Thus the time constants for these circuits changed with humidity and the indicated glass level would drift off scale. These timing circuits were either replaced with crystal-controlled timers or were placed in sealed compartments with a desiccant to alleviate this prob1em. The signal drift reoccurred in the most recent test (PSCM-21) of the TDR. Examination of the electronics by the vendor revealed that the desiccant had been consumed, that a circuit to a RS-232 printer port had burned out and that there was an additional signal drift associated with the initial power-up of the instrument. At the time of this writing, these problems had not been completely corrected.

The electrical noise created by the phase-angle-fired melter power supplies also initially induced errors in the indicated glass levels. This problem was solved by forcing the TDR to perform its function during the portion of the AC cycle that the SCRs are open circuited.

During PSCM-19, the TDR probe was located in the north rectangular flange, just south of the IR camera. In this position, the probe tended to form a dam with feed bridging between the two Inconel rods, effectively preventing the cold.cap from enlarging toward the north end of the melter. This feed accumulation also induced liquid-level indication errors from the TOR system. The camera and TDR probe positions were reversed during PSCM-20 and PSCM-21 such that the probe was farther from the center of the melter and the feed nozzle. No blockage of the cold cap was observed with the TDR in this location.

Large quantities of glass hairs formed during PSCM-21 and collected in the melter plenum including on the TDR probe. These hairs formed a crust across both Inconel rods beginning approximately $5 \mathrm{~cm}$ above the giass/cold cap level and extending up the rods at least $20 \mathrm{~cm}$. It is not clear if the crust formed a short across the rods because the electronics were drifting significantly during the run. Alternative probe designs should be considered if accumulation 
of the probe rods becomes a problem. Several self-cleaning probe designs have been proposed by the vendor although simpler concepts such as those shown in Figure 31 also are promising.

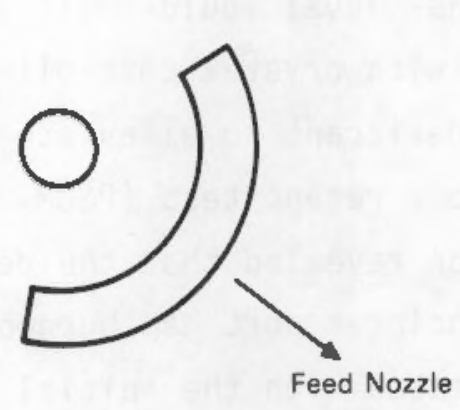

a) Concentric probe with cold cap shield.

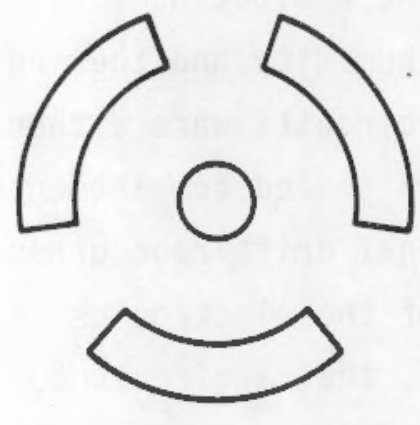

b) Concentric probe with additional shielding.

\section{FIGURE 31. Alternative TDR Probe Designs}

\section{RECOMMENDATIONS}

Testing of the time-domain reflectometer has been hampered by problems with the electronics and the probe design for the TDR. The concept is attractive but unless and until the TDR can receive extensive testing in glass melters, its value to LFCM monitoring and control will remain unresolved. 


\section{CONCLUSIONS}

Instrumentation is being developed and evaluated for monitoring and control of the liquid-fed glass melting process for treatment of liquid radioactive wastes. Thermocouples are used extensively throughout the melter

process. A bubbler diptube system is used to measure glass level and to detect foaming. An infrared camera is being evaluated as a tool to provide remote pictures of the glass/cold cap surface. Time domain reflectometry is being considered for glass level detection and acoustic monitoring is being examined for detection of foaming and overfeeding.

Temperatures are a critical indicator of the glass melting process to assure that a quality product is being produced and that the melter equipment is in good operating condition. Additional information about the operation of the melter including foaming, feeding and cold cap coverage, and glass transfers can be obtained from temperature data.

As has been generally recognized, foaming is characterized by an increase in temperatures at all levels in the glass melt. Still to be resolved is how to identify this temperature increase amid all the random temperature fluctuations associated with the convection currents in the melter. It appears that clustering thermocouples in the region of the cold cap may provide an early indication of the onset of foaming.

GTass transfers from the melter are indicated by temperature increases measured with thermocouples located in the area of the discharge trough and face and with thermocouples located near the meiter floor by the discharge entrance.

Plenum temperatures give an indication of the cold cap coverage. Typically, the higher the plenum temperatures and the greater the separation in temperature from top to bottom of the plenum thermowell, the smaller the cold cap. It appears that during overfeeding, the temperature profile inverts with cooler temperatures closer to the cold cap. It will be difficuit to develop a quantitative relationship between cold cap coverage and plenum temperatures. off gas temperatures may provide some information on the melting process but additional work is needed. 
The pneumatic level detection system functions well for measuring glass specific gravity and level in the melter. The bubbler is designed to also provide indications of overfeeding, bridging of the cold cap, and foaming. Corrosion is a potential problem with the bubbler and with all instrumentation within the molten glass and melter plenum.

The melter viewing system consisting of an infrared camera and associated electronics has been demonstrated to provide clear pictures of the melter interior and cold cap surface during melter operation. Additional design work is needed to provide adequate cooling to critical components within the melter cavity and to provide pictures of the entire glass surface so that quantitative estimates of cold cap size can be made.

Additional development and evaluation is needed before the feasibility of the acoustic probe and the time domain reflectometer can be determined. The acoustic probe appears to respond to changes in the glass/cold cap region but no strong correlations have been established. The time domain reflectometer has been plagued by problems with the electronics of the system so the evaluation is incomplete. 


\section{REFERENCES}

Bird, R. B., W. E. Stewart, and E. N. Lightfoot. 1960. Transport Phenomena, John Wiley \& Sons, Inc. New York.

Heckendorn, F. M., II. 1983. "DWPF Process Control," Waste Management 1983, University of Arizona, Tucson, Arizona. 
DISTRIBUTION

No. of

Copies

OFFSITE

30 DOE Technical Information Center

7 OOE Office of Terminal Waste Disposal \& Remedial Action GTN

Washingt on, D.C. 20545

ATTN: J. E. Baublitz, NE-24

J. A. Coleman, NE-25

0. J. McGoff, $N E-23$

J. A. Turi, NE-25

W. R. Voigt, NE-20

H. F. Walter, $N E-25$

J. B. Zorn, NE-25

Geologic Repository Division DOE Office of Civilian

Radioactive Waste Management

Forrestal Building

Washington, DC 20545

2 DOE Office of Defense Waste \& GTN

Byproducts Management

Washington, DC 20545

ATTN: D. B. LeClaìre, DP-12

R. D. Walton, ur.,

$\mathrm{DP}-123$

M. J. Bell

Division of Nuclear Materials Safety \& Safeguards

Mail Station 881-SS

Nuclear Regulatory Commission

Washington, DC 20555

A. T. Clark

Division of Fuel Material

Safety

Nuclear Regulatory Cormission

Washington, DC 20555
No. of

Copies

W. J. Dircks

Office of the Executive Director for Operations

Mail Station 6209

Nuclear Regulatory Commission

Washington, DC 20555

2 Environmental Protection Agency

Office of Radiation Programs

401 M Street, S.W.

Washington, DC 20460

ATTN: D. Egan

G. L. Sjoblom

DOE Albuquerque Operations

Office

P.0. Box 5400

Albuquerque, NM 87185

ATTN: R. Y. Lowrey

W. H. Hannum

DOE West Valley Operations Office

P.O. Box 191

West Valley, NY 14171

2 DOE Idaho Operations Office

550 Second Street

Idaho Falls, ID 83401

ATTN: J. D. Hamric

J. B. Whit sett

L. Lanni

DOE San Francisco Operations 1333 Broadway

San Francisco, CA 94612

W. E. Pasko

DOE Oak Ridge Operations office P.0. Box E

Oak Ridge, TN 37830 
No. of

Copies

G. K. Dertel

DOE Savannah River Operations Office

P.0. Box A

Aiken, SC 29801

2 Argonne National Laboratory

9700 South Cass Avenue

Argonne, IL 60439

ATTN: C. S. Arbans/

J. H. Kittel

M. J. Steindler/

L. E. Trevorrow

F. Holzer

Lawrence Livermore National

Laboratory

University of California

P.0. Box 808

Livermore, CA 94550

Los Alamos Scientific Laboratory

MS 671

P.0. Box 1663

Los Alamos, NM 87544

ATTN: D. T. Oakley

T. H. Row

Oak Ridge National Laboratory

P.0. 80x $X$

Oak Ridge, TN 37830

2 Oak Ridge National Laboratory

P.0. 80x Y

Oak Ridge, TN 37830

ATTN: J. 0. Blomeke

W. D. Burch

Sandia Laboratories

P.0. Box 5800

Albuquerque, NM 87185

ATTN: Technical Library
No. of

Copies

B. R, wheeler

Westinghouse Idaho Nuclear Co., Inc.

P.0. Box 4000

Idaho Falls, ID 83401

7 E. I. du Pont de Nemours \& Company

Savannah River Laboratory

Aiken, SC 29801

ATTN: M. D. Borsma

E. J. Hennelly

L. L. Ki Tpatrick/

L. M. Lee

S. Mirshak

R. M. Wallace

F. M. Heckendorn

J. F. Ortaldo

EG\&G Idaho

P.0. 80x 1625

Idaho Falls, I0 83415

ATTN: E. A. Jennrich

8 West Valley Nuclear Services

Company

P.0. Box 191

West Valley, NY 14171-0191

ATTN: J. C. Cwyner

L. R. Eisenstatt

J. L. Knabenschuh

J. E. Krauss

J. M. Pope

S. M. Barnes

C. C. Chapman

N. E. Chapman

ONSITE

4 DOE Richland Operations Office

E. A. Bracken

J. J. Broderick

M. W. Shupe

J. D. White 
No. of

Copies

7 Rockwell Hanford Operations

R. N. Gurley

J. M. Henderson

R. D. Prosser

K. R. Shah

R. J. Thompson

D. D. Wodrich

File Copy

UNC United Nuclear Industries

T. E. Dabrowski/W. J. Kyriazis

2 Westinghouse Hanford Company

R. E. Lerch

J. D. Watrous

58 Pacific Northwest Laboratory

W. J. Bjorklund

W. F. Bonner

J. L. Buelt

H. C. Burkholder

J. R. Carrell

T. D. Chikalla

R. D. Dierks
No. of

Copies

V. F. FitzPatrick

M. S. Hanson

L. K. Holton

J. H. Jarrett

D. E. Knowlton

W. L. Kuhn

L. T. Lakey/K. M. Harmon

J. M. Latkovich

R. C. Liikala/M. R. Kreiter

D. McCarthy

J. L. McElroy

G. L. McVay

J. E. Minor

R. K. Nakaoka

J. M. Perez, Jr.

R. D. Peters

A. M. Platt

J. V. Robinson

N. L. Scharnhorst

P. A. Scott

G. J. Sevigny

N. M. Sherer

D. H. Siemens

G. E. Spanner

J. H. Westsik (20)

Technical Information (5)

Publishing Coordination (2) 
